\title{
Building Operations Efficiencies Into NASA's Ares I Crew Launch Vehicle Design
}

\author{
Daniel L. Dumbacher \\ Deputy Director \\ Exploration Launch Projects Office \\ NASA Marshall Space Flight Center \\ Huntsville, Alabama 35812
}

\begin{abstract}
The U.S. Vision for Space Exploration guides the National Aeronautics and Space Administration's (NASA's) challenging missions that expand humanity's boundaries and open new routes to the space frontier. With the Agency's commitment to complete the International Space Station (ISS) and to retire the venerable Space Shuttle by 2010, the NASA Administrator commissioned the Exploration Systems Architecture Study (ESAS) in mid 2005 to analyze options for safe, simple, cost-efficient launch solutions that could deliver human-rated space transportation capabilities in a timely manner within fixed budget guidelines. The Exploration Launch Projects Office, chartered in October 2005, has been conducting systems engineering studies and business planning over the past few months to successively refine the design configurations and better align vehicle concepts with customer and stakeholder requirements, such as significantly reduced life-cycle costs. As the Agency begins the process of replacing the Shuttle with a new generation of spacecraft destined for missions beyond low-Earth orbit to the Moon and Mars, NASA is designing the follow-on crew and cargo launch systems for maximum operational efficiencies. To sustain the long-term exploration of space, it is imperative to reduce the $\$ 4.5$ billion NASA typically spends on space transportation each year. This paper gives top-level information about how the follow-on Ares I Crew Launch Vehicle (CLV) is being designed for improved safety and reliability, coupled with reduced operations costs.
\end{abstract}




\section{Introduction}

NASA is revitalizing the Nation's space fleet and is re-vectoring the way the Agency does business. It is seeking potential efficiencies across the Agency's mission portfolio by providing a routine, steady market for logistics and crew rotation services to the Space Station through the Commercial Orbital Transportation Services demonstration. ${ }^{1}$ Yet, while being flexible, the Agency has a overriding responsibility to assure U.S. access to space, as is evidenced in its methodical pursuit of a new humanrated transportation system that can be ready for crew travel to low-Earth orbit no later than 2014, as well as cargo transportation to the Moon no later than 2020. These systems will be extensible to future systems that one day will enable the first human footprint on Mars.

Given these strategic goals and objectives, as are outlined in the U.S. Vision for Space Exploration, NASA's Exploration Launch Projects Office has enacted implementation tenets that include utilizing current and proven technologies to the maximum extent possible (see Fig. 1). ${ }^{2}$ Areas of potential recurring cost savings being investigated include designing a robust system with automated processing for reduced touch-labor, easy access to components for maintenance, commonality among ground support equipment, and the ability to perform standard automated mission profiles without undue operator intervention. Sample requirements that address such issues include launch-on-time probability and launch availability in relation to weather constraints.

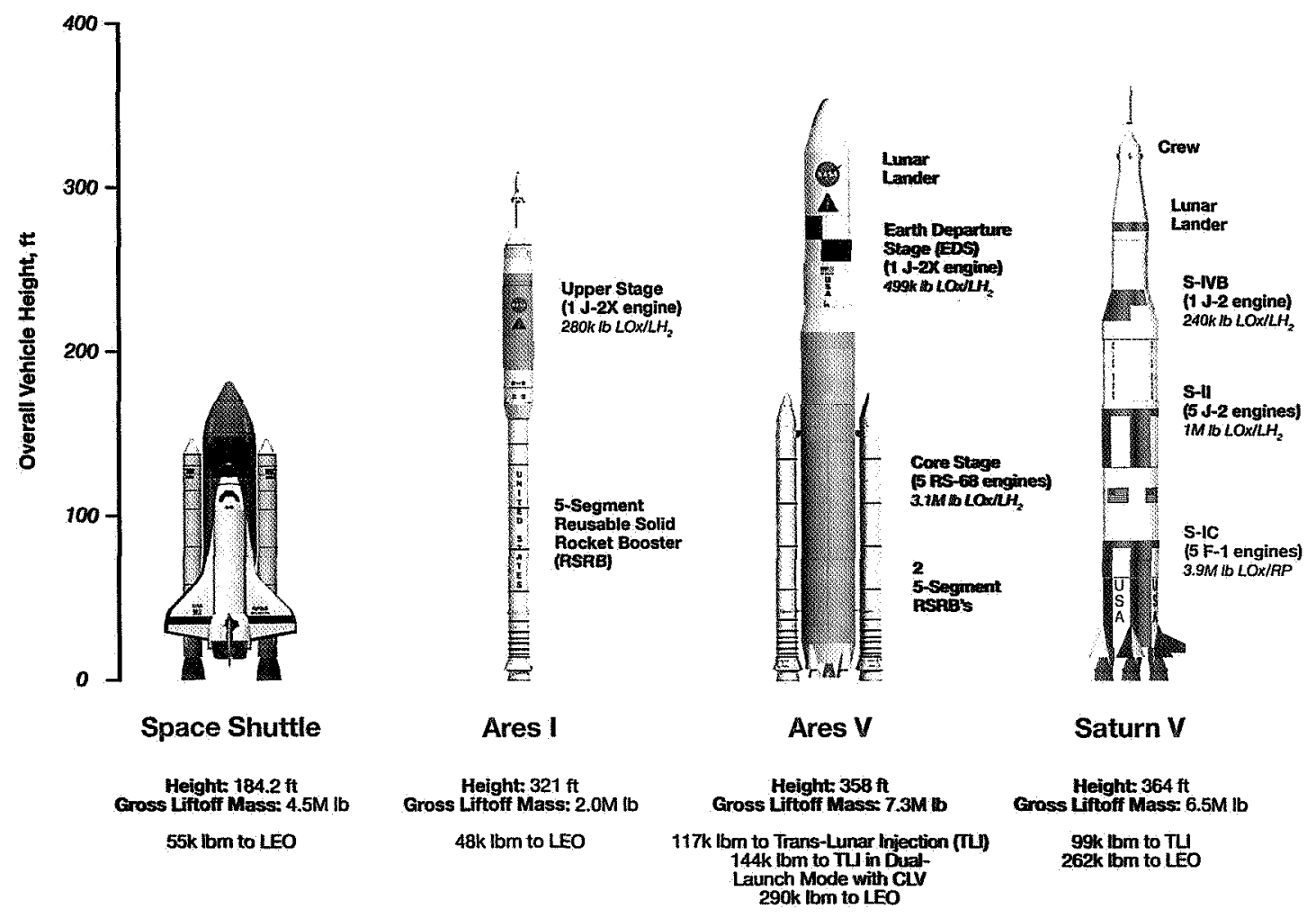

Fig. 1. Comparison of the Shuttle and Saturn to the Ares I and Ares V (arrows indicate hardware evolution and commonality). 
This paper addresses how the Exploration Launch Projects Office is designing operational efficiencies into the Ares I Crew Launch Vehicle configuration, which was selected based on figures of merit that included safety and reliability, coupled with significant decreases in operations costs to sustain the Nation's space exploration mission across the decades ahead. It includes a summary of the systems engineering approach to delivering capabilities that fulfill well-defined customer and stakeholder requirements, including trade studies conducted against the initially recommended design.

To provide a background for the work now in progress, NASA released the results of the Exploration Systems Architecture Study (ESAS) in fall 2005. The ESAS team of Government experts measured both Shuttle-derived and expendable launch vehicle options against figures of merit in relation to design reference missions to the Space Station and the Moon, in preparation for the first astronaut visits to Mars. ${ }^{3}$ Subsequently, the Exploration Systems Mission Directorate and the Constellation Program chartered the Exploration Launch Projects Office to design, develop, test, and evaluate (DDT\&E) the Ares I transportation system for the Crew Exploration Vehicle (CEV) (see Fig. 2), as well as the Ares V heavylift cargo system for the Lunar Surface Access Module (LSAM) payload (see Fig. 3).

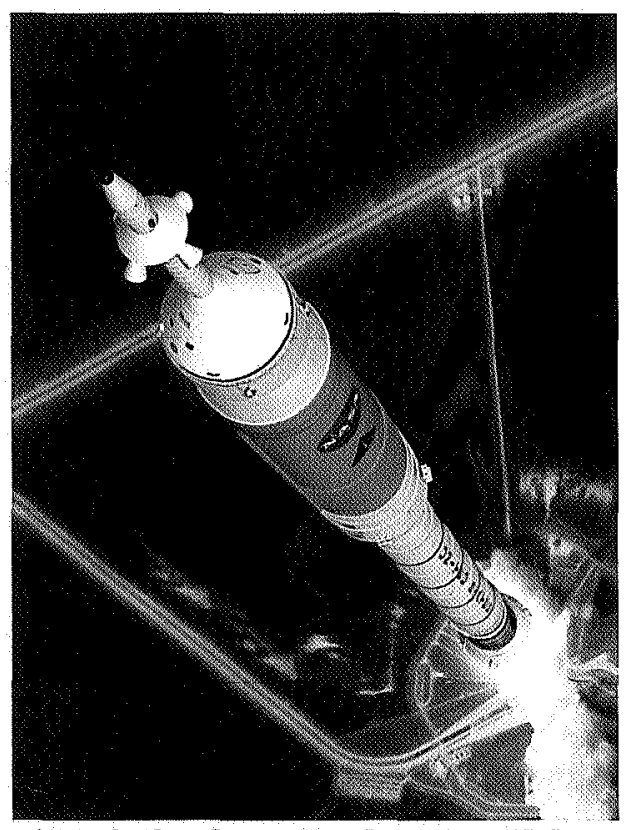

Fig. 2. The Ares I will loft the Crew Exploration Vehicle (artist's concept).

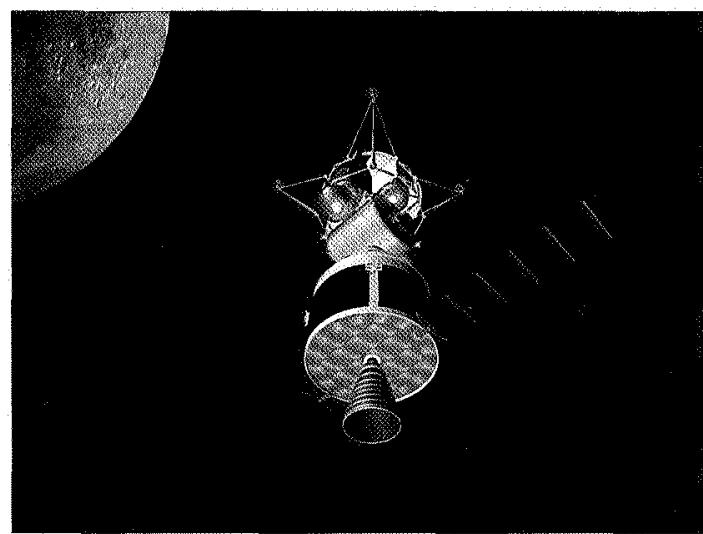

Fig. 3. The Ares V will loft the Lunar Surface Access Module, shown docked with the Crew Exploration Vehicle (artist's concept). 
The current Ares I concept, shown in Fig. 4, is an in-line configuration that places the Crew Exploration Vehicle on top of the integrated stack. The Launch Abort System on top of the Crew Exploration Vehicle is designed to move the capsule away from the stack in case of a launch emergency. As stated above, the Agency's hardware approach is to build upon existing technologies to the maximum extent possible - the Ares I first stage is a 5-segment Reusable Solid Rocket Booster, much like the 4segment used on the Space Shuttle today - and the in-house designed upper stage will be powered by a $\mathrm{J}-2 \mathrm{X}$ engine, an evolution of that used on the Saturn V upper stages. Likewise, as is shown in Figs. 1 and 6, hardware commonality with the Ares V is a development approach that is expected to reduce both nonrecurring and recurring costs. With an eye toward fielding, NASA has awarded study contracts to examine the long-term ground processing and infrastructure planning for future launch services. ${ }^{4}$ The Ares I vehicle system designers also are planning for operations efficiencies utilizing various approaches and through a number of avenues.
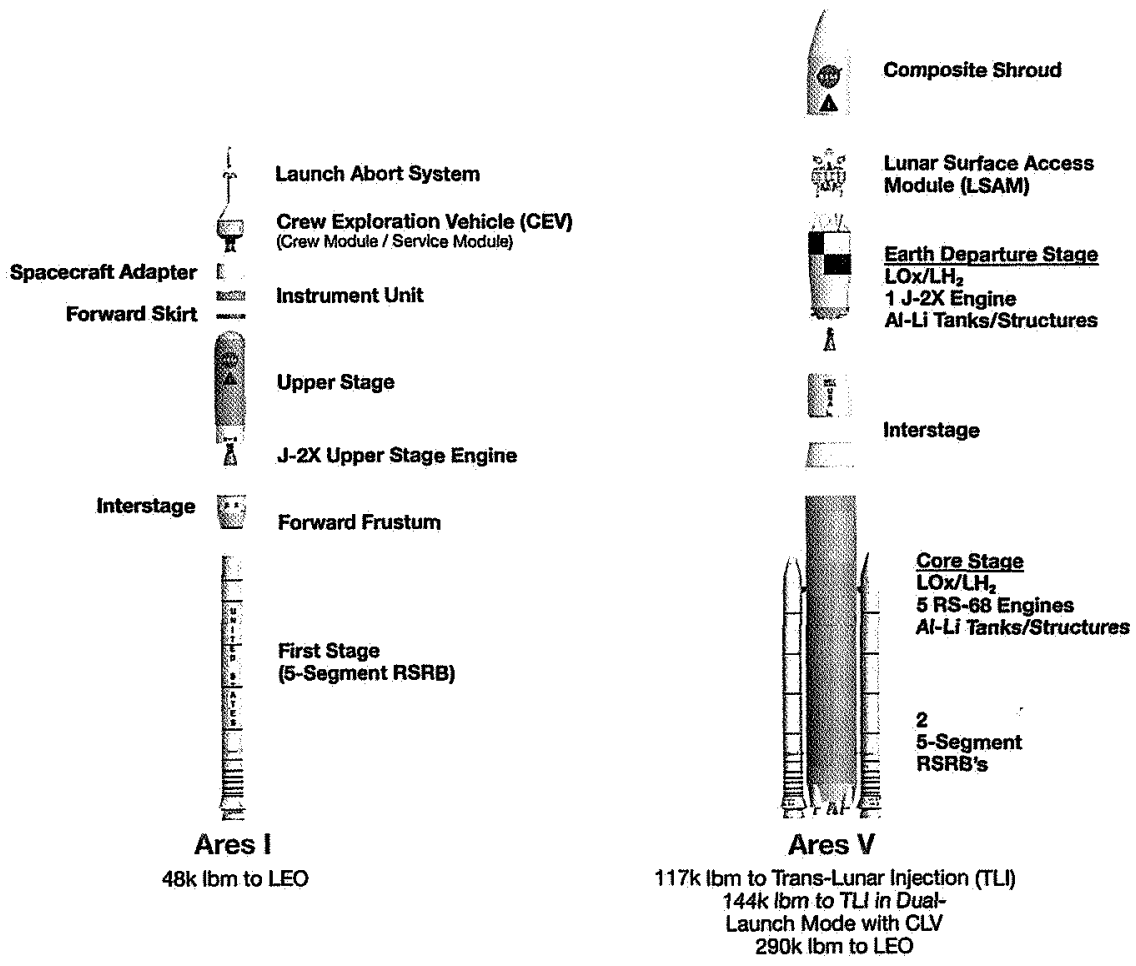

Fig. 4. Ares I and Ares V expanded views.

Given below is a summary of the systems engineering approach implemented by the Exploration Launch Projects team to refine vehicle concepts using decades of knowledge, while applying the latest in measurement methodologies, tools, and techniques, with an eye on affordability as a performance metric, closely following safety and reliability. Systems engineering provides a framework for the operability design and analysis discipline, within which costs are viewed as an independent variable in making judgments that affect a range of factors, and the integrated operations and logistics discipline, which considers and coordinates all aspects of safety, reliability, maintainability, supportability, and affordability in the up-front requirements design and development activities. As is discussed below, the Agency's two-prong approach - managing requirements and measuring associated operations costs at various check-points - is essential to driving operability into the design, as an integral part of the process. 


\section{Systems Engineering and Integration Approach}

Systems engineering reduces risk by providing a strong linkage between and among disparate engineering disciplines, from aerodynamics and avionics to mass properties and thermal control. The Exploration Launch Projects Office implements systems engineering standards to improve accuracy and reduce rework. Through systems engineering, trade study analyses are performed to determine the optimum solutions that fulfill customer and stakeholder requirements, focusing on the "-ilities," such as reliability, maintainability, supportability, operability, and affordability.

The Exploration Launch Projects' Vehicle Integration Element understands the synergy that results when the pieces are fused into the whole system. The Vehicle Integration Element facilitates communication via embedded staff members throughout the various hardware offices, as well as through on-site residents located at geographically dispersed business units, including manufacturing, testing, and ground processing facilities. This organizational element is invested with the methods and means to ensure correct and proper functionality, and employs a formal review process to validate findings and make recommendations to the Constellation Program.

\section{A. Decision Gates}

NASA conducts a series of internal and independent reviews throughout the project's life cycle to serve as check-points for a number of engineering products, such as drawings and specifications, and to gauge progress against established funding guidelines and schedule milestones. ${ }^{5}$ Non-advocate reviews survey technical and programmatic documentation and provide forums for interactive discussions relative to project progress and to validate that success criteria have been met. Other independent audits are conducted throughout the DDT\&E activities.

Following a rigorous configuration management process provides a framework for disciplined innovation as resources are marshaled to fine-tune concepts and plans, leading to the Ares I System Requirements Review, currently planned for autumn 2006, followed by the Preliminary Design Review in spring 2008. ${ }^{6}$ At the Ares I System Requirements Review, the Constellation Program and lower-level requirements will be baselined, forming a foundation upon which further trade studies will be performed, leading to specific designs that will be baselined at the Ares I Preliminary Design Review.

Table 1 shows the series of internal reviews that are conducted to ensure that the design is sufficiently mature and that requirements are fully understood and accounted for, in order to proceed to the development phase, as directed by NASA's Program and Project Management regulation and its Systems Engineering guidelines. ${ }^{7}$ These decision gates have well-defined entrance and success criteria against which to measure a multitude of inputs.

For example, the first ascent flight test of the Ares I, known as Ares I-1, will support the Critical Design Review assessment and evaluations. Specifically, the primary test objectives include:

- Demonstrate control of a dynamically similar, integrated Ares I with Crew Exploration Vehicle, using Ares I ascent control algorithms.

- Perform a nominal in-flight separation/staging event between an Ares I similar first stage and representative upper stage.

- Demonstrate assembly and recovery of a new Ares-like first stage element at the Kennedy Space Center

- Demonstrate first stage separation sequencing and quantify first stage atmospheric entry dynamics and parachute performance.

- Characterize magnitude of integrated vehicle roll torque through first stage flight. 
Table 1. NASA internal technical reviews.

\begin{tabular}{|c|l|}
\hline $\begin{array}{c}\text { Review Title } \\
\text { (SRR) }\end{array}$ & \multicolumn{1}{c|}{ Review Purpose/Outcome } \\
\hline $\begin{array}{c}\text { System Requirements Review } \\
\text { (PDR) }\end{array}$ & $\begin{array}{l}\text { Assures that requirements are properly defined, verifiable, and implemented, } \\
\text { are traceable, and that the hardware and software are designed and built to } \\
\text { the authorized baseline configuration. }\end{array}$ \\
\hline $\begin{array}{c}\text { Preliminary Design Review } \\
\text { (CDR) }\end{array}$ & $\begin{array}{l}\text { Provides completed design specifications, the identification and acquisition } \\
\text { of long-lead items, manufacturing plans, and life cycle cost estimates; the } \\
\text { design is 30\% complete and element specifications are baselined. }\end{array}$ \\
\hline $\begin{array}{c}\text { Design Certification Review } \\
\text { (DCR) }\end{array}$ & $\begin{array}{l}\text { Discloses the complete system in full detail; ascertains that technical } \\
\text { problems and design anomalies have been resolved; and ensures that the } \\
\text { design maturity justifies the decision to begin fabricating/manufacturing, } \\
\text { integration, and verification of mission hardware and software. The design is } \\
\text { 90\% complete. }\end{array}$ \\
\hline $\begin{array}{c}\text { Flight Readiness Review } \\
\text { (FRR) }\end{array}$ & $\begin{array}{l}\text { Serves as the control gate that ensures the system can accomplish its mission } \\
\text { goals. Requirements are verified in a manner that supports launch } \\
\text { operations. }\end{array}$ \\
\hline $\begin{array}{l}\text { After the system has been configured for launch, the FRR process examines } \\
\text { tests, demonstrations, analyses, and audits that determine the system's } \\
\text { readiness for a safe and successful launch and for subsequent flight } \\
\text { operations. The Project Manager and Chief Engineer certify that the system } \\
\text { is ready for safe flight. }\end{array}$ \\
\hline
\end{tabular}

Experts estimate that at least 80 percent of space transportation system life-cycle costs is "locked in" by the concept that is chosen, which is during the System Requirements Review process. This means that further design work after this point has very little effect on reducing manufacturing and operations expenses. ${ }^{8}$ Although human-rated launch vehicles are more on the order of prototypes, rather than massproduced such as military and commercial aircraft, the information collected as legacy systems were designed and fielded provides a valuable database of actual investments on which to rate cost-to-benefit assessments during the requirements validation process leading up to the System Requirements Review.

\section{Managing Requirements}

Given the record of past and present launch vehicle costs, the most immediate and persistent action the Exploration Launch Projects team can take to reduce non-recurring investments and long-term lifecycle expenses is to manage requirements in an accountable manner, delivering the required launch capability on time and within budget. The Ares I design team is focused on the end product, ensuring that precious time and energy are expended on value-added activities that drive strategies into measurable results.

Requirements "creep" can skew budget and schedule to the point that the effort collapses under its own weight. Learning from past experiences, the design team judiciously manages requirements definition and decomposition through control boards and its checks-and-balances organizational network. For example, the Vehicle Integration Element performs extensive systems engineering functions across the hardware elements (First Stage, Upper Stage, and Upper Stage Engine), while Safety and Mission Assurance representatives and chief engineers are embedded for independent insight and vertical penetration. Risk and investment-to-benefit assessments are conducted against validated requirements in trade spaces that include cost as an independent variable, where actual and projected budgets are analyzed against schedule and technical performance. The process of functional decomposition flows derived requirements from the system level, to the element level, to the component level to ensure that the design will satisfy its intended mission. These requirements are verified through the systems engineering and integration process. 
This section provides an overview of NASA's guiding requirements that form the basis for trade studies conducted against the point of departure baseline configuration. Such analyses assist in identifying challenges and developing plans to mitigate risks. For example, during the course of several design analysis cycles, the ESAS-recommended configuration has been systematically refined into one that provides maximum extensibility to the Ares V, which is in the early planning stages. This approach reduces technical, schedule, and cost risks by reducing the number of separate propulsion developments required to field a new human-rated space transportation capability and its heavy-lift cargo companion. Guided by the Agency's Constellation Architecture Requirements Document (CARD), rocket engineers and business professionals employ the latest in methods and tools as they pursue the optimum space transportation solution to work in tandem with the Ares V to replace the Space Shuttle system for the continued human exploration of space. ${ }^{9}$

\section{A. Constellation Architecture Requirements Document}

The ultimate goal of the Exploration Launch Projects office is to deliver safe, reliable crew and cargo systems designed to minimize life-cycle costs so that NASA can concentrate on missions of scientific discovery. To that end, the Space Shuttle follow-on systems are being designed and developed within the safety, reliability, and cost figures of merit provided, in conjunction with design reference missions that clearly define the various exploration-related destinations ahead. Together, these aspects form a trade space that is bounded by top-level requirements that are decomposed to lower system levels.

As is shown in Fig. 5, the Exploration Systems Mission Directorate's Implementation Plan flows into the Constellation Architecture Requirement Document, which informs the Crew Launch Vehicle and Cargo Launch Vehicle System Requirements Documents (SRDs). At lower levels, each launch vehicle subsystem, or element, is governed by an Interface Requirements Document, which details the various linkage points (such as command and control, power, communications, and mechanical interfaces), and by an operations concept, which covers the multitude of aspects that go into integrating the vehicle subsystems, and payloads, and launching the integrated stack. Furthermore, a series of flight demonstrations - from simulators to high-fidelity vehicles - will provide the opportunity to validate modeling and simulation, test mission scenarios and the human/mechanical interface, and further influence integration and operations decisions. These and other risk mitigation strategies are being employed to improve communication and ensure that as-built hardware conforms with design parameters and associated requirements

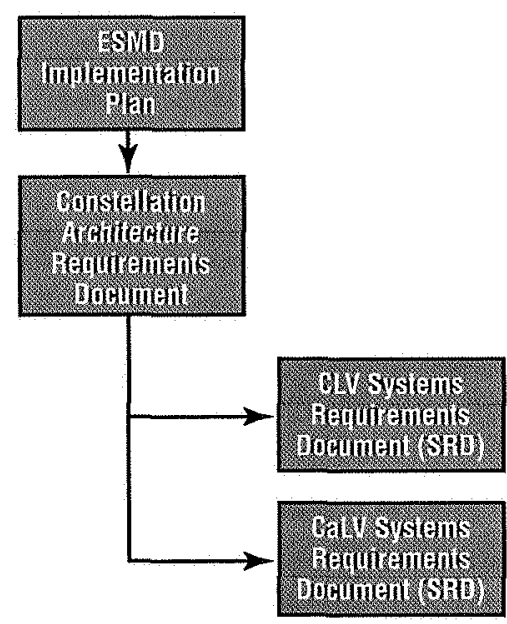

Fig. 5. High-level requirements flow down to system and subsystem requirements to facilitate integration. 
Given below is a top-level overview of two primary requirements, as set forth in the CARD, which permeate design activities:

- Extensibility and Flexibility - The Constellation Program will use an evolutionary approach to expanding human presence in the solar system. Incremental, cumulative achievements can be leveraged in the design of next-generation systems. Designs should strive to address future requirements, while fulfilling their primary mission needs. Designs should strive to maximize operational flexibility to accommodate changing mission needs.

- Life-cycle Costs - A sustainable program hinges on how effectively total life-cycle costs are managed. Developmental costs are a key consideration, but total life-cycle costs related to the production, processing, and operation of the entire architecture must be accounted for in design decisions to ensure future resources are available for ever more ambitious missions. Historical data show that these costs are set within the first 10 percent of its life and that design solutions to problems encountered during development often are not adequately scrutinized for their potential impacts on ground and/or mission operations impacts over the balance of the program. The Constellation Program will aggressively manage this aspect using design policies and simple solutions.

The following gives a summary of the system design policy, guidance, and objectives, also set forth in the CARD:

- Risk Management - The primary criterion is to achieve mission success with the least risk to safety.

- Reliability - The primary means of achieving crew safety and mission success. Every effort should be made to minimize uncertainty, through the use of reliability methodologies and demonstrations. Backup systems may be required to enhance crew survival. In-flight maintenance processes should be provided, where practicable. New technology developments should be recommended only if reusing existing technologies is unsuitable.

- Design Guidance - Flight equipment and associated ground and mission equipment and procedures should accommodate the various flight tests and vehicle configuration that are planned, with minimum variation of the equipment from flight to flight. The feedback loop and linkages between operational performance and system design are particularly important to maximize learning during the long-term development process. The organizational structure will be self-reflective, self-analytical, sustainable, adaptable, and capable of applying lessons learned in a timely manner.

- Design Robustness - A product is robust when it is insensitive to the effects of sources of variability, performing consistently as intended throughout its life cycle, under a wide range of user conditions and outside influences. Designing for high reliability and redundancy alone is not sufficient to achieve design robustness. Reliability is the probability that a system will perform its intended mission under specific conditions. Robustness is the ability of the system to operate outside of specified operating parameters. Application of a robust design can improve operational flexibility, cost effectiveness, and schedule.

Some of the methods for achieving these requirements are discussed below in relation to the Ares I Operations Concept, which describes the manufacturing, assembly, and operational system characteristics and scenarios. It also captures the operational requirements, based on timelines (turnaround, launch availability/probability, etc.) and in consideration of program constraints (for example, existing infrastructure) and the mission manifest. The Exploration Launch Projects' Systems Engineering Management Plan is a companion document that provides the framework for engineering disciplines investigating factors such as maintainability, interoperability, and supportability. These and other reliability-related design studies and logistics planning activities are narrated below. 


\section{B. Operations Concept}

The cost of access to space limits the budget that can be invested in the missions that space transportation enables. The Constellation Program, with its long-term implementation horizon, requires increased operational efficiencies. At this early stage, the management of these requirements across the Program and Project will drive success.

The business of delivering new space transportation capabilities includes operations concepts that reduce both recurring costs, such as propulsion element production and sustaining engineering and processing the integrated launch vehicle stack, and nonrecurring costs, such as modifying the existing launch infrastructure to accommodate these new systems. By studying the pros and cons of past and present launch vehicle processing, plans are for the various hardware elements to arrive at the launch facility in pre-configured sets (i.e., the engine will be mated with the upper stage element) for streamlined handling.

The Operations Working Group, as a subset of the Vehicle Integration Office and part of the Constellation Ground and Mission Operations Systems Integration Group, ensures that logistics and other details are considered as part of the overall operations concept and requirements development. The Ares I Operational Concepts document is key to the decision-making process in terms of reducing non-recurring costs related to DDT\&E and recurring expenses related to launch processing and ground and mission operations. ${ }^{10}$ The Operations Concept document tree in Fig. 6 shows how requirements flow down from the Ares I System Requirements Document, Element Interface Requirements Documents (IRDs), and Interface Control Documents (ICDs) to lower level specifications.

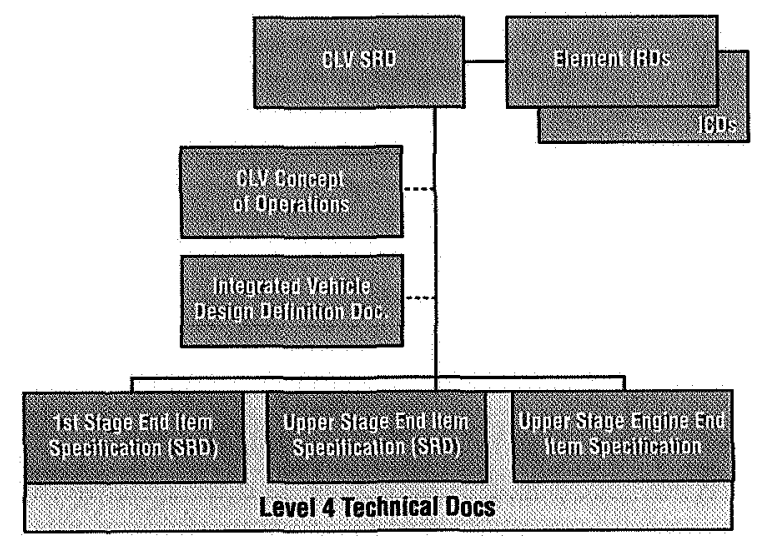

Figure 6. Operations Concept document tree.

A sample of Ares I ground and flight operations goals include:

- Processing time of no longer than 60 days from receipt at launch site to launch.

- Elements should arrive with no open factory work, except in special pre-approved cases.

- Launch scrub turnaround time of not more than 24 hours, when not hardware related.

- Minimal ground interfaces to simplify operations, maximize reliability, and reduce infrastructure.

- Common ground support equipment (for example, processing stands).

These and a wide variety of other operational considerations are taken into account by design engineers as they analyze the lower-level requirements levied on hardware and software component selection. 
A selection of methodologies and tools is provided following an overview of the operability design and analysis discipline, which integrates safety, reliability, availability, and affordability in the flight hardware design to obtain a safe, reliable, and cost-effective system. Also discussed below is the integrated operations and logistics discipline, which implements flight hardware operability design into the total launch system, including the processing, integration, testing, and checkout activities, and the launch facilities and supporting infrastructure modifications now under consideration.

\section{Operability Design and Analysis/Integrated Operations and Logistics}

The Exploration Launch Projects' Systems Engineering Management Plan documents the formal organizational structure of working groups, integrated product teams, and boards that review and approve engineering analyses and recommendations. ${ }^{11}$ It defines the various engineering disciplines that, collectively, drive down costs through efficient, effective design solutions. For example, reliability, maintainability, supportability, manufacturability, affordability, and operability engineering combine to reduce design risk and enhance mission success.

In previous launch vehicle developments, cost performance has been eclipsed by technical performance concerns. With a commitment to the Agency's "pay as you go" philosophy, the Exploration Launch Projects Office has organized to effectively address this critical performance parameter. As discussed in the Systems Engineering Management Plan, operability engineering is a field that influences the design process, beginning with the initial design and lasting throughout the life cycle, to ensure that the Ares I meets system operability metrics. Operability design and analysis is a specialized subset of systems engineering and integration, which takes a risk-based management approach to understanding and predicting performance and behavior. Its companion - integrated operations and logistics - closely coordinates activities with those of the operability design and analysis team to ensure that hardware operability is continually addressed throughout the new space transportation system's life.

Operability design and analysis focuses on flight hardware safety, reliability, manufacturability, maintainability, and supportability as they impact the operability of the flight configuration. Since operability directly affects the system's recurring costs and availability, the management of related requirements are within the purview of operability design and analysis activities. Tasks include hazards analysis, fault tree analysis, failure logic modeling, reliability modeling and analysis, maintainability modeling, launch availability analysis, supportability modeling and analysis, and integrated vehicle dynamic modeling.

The integrated operations and logistics field looks at the process or series of tasks involved in a particular form of work, with an eye toward just-in-time logistics. Integrated operations involve the analysis and integration of all launch system functions that, when performed correctly, result in the successful launch and flight of the Ares I. These functions include: maintenance, processing, stacking, fueling, servicing, testing, and checkout, and launch and mission operations. Although primarily focused on functions performed at the launch site, the total launch system includes the ability to provide expendable elements and replace reusable items.

Logistics support engineering identifies the resources that are required to support a system once it is deployed. Sub-disciplines include: training, technical publications, and provisioning. Products include the operations concept, maintenance concept, logistics support plan, and hardware and assembly plan, among others. Integrated operations and logistics tasks include: level-of-repair analysis, line replaceable unit analysis, spares modeling, operational readiness analysis, maintenance downtime modeling and analysis, and maintenance task analysis. 
A thorough understanding of the design and how it affects operability, as well as logistics and operations, is a key component for ultimately reducing Ares I life-cycle costs. Engineers who specialize in these fields use a variety of tools to makes estimates about how design decisions will affect the range of -ilities - safety, reliability, manufacturability, maintainability, supportability, availability, and affordability - each which contributes to overall development investments and fixed operations costs. For example, a thorough assessment of the Critical Items List that results from the Failure Modes and Effects Analysis will help identify solutions other than costly hands-on inspections after the hardware reaches the launch site. Learning from the Shuttle experience, engineers will scrub this list of potentially catastrophic hardware failures to identify retention rationale, to discover where design changes might minimize the number of items on the list, and to potentially perform such inspections at the assembly floor or in other ways that are less intrusive, resulting in cost efficiencies.

\section{Methodology and Tools}

Engineering and business information technologies are employed to effectively manage change; to estimate, track, and forecast resource utilization; and to determine technical progress against milestones captured in a logic-linked integrated master schedule. These and other systems engineering and systems management processes and procedures also build on a heritage foundation to give confidence that the launch vehicles fielded next decade can deliver the operational capability required more economically than current systems. From a management-systems perspective, the Exploration Launch Projects team depends on tools such as a comprehensive configuration management process, as well as on rigorous internal and independent reviews that serve as decision gates on the path to delivering new space transportation capabilities. Supporting methodologies are based on sound engineering standards and objective scientific practices.

Discipline experts employ a portfolio of state-of-the-art tools and statistical models for calculating factors such as loss of crew and loss of mission. For example, the operability design and analysis group uses the failure logic model, which combines failure modes and effects analysis and related analysis in one step, with the development of the failure logic (e.g., fault tree, event tree, etc.) to facilitate risk-based management. Availability modeling determines the probability that a system or piece of equipment will operate satisfactorily at any point in time. Affordability cost modeling determines if the life-cycle cost of an acquisition is in consonance with long-range investment and mission plans, in other words, how well the proposed life-cycle cost fits within the available budget.

Mining information from past databases to develop credible designs is accomplished through a number of innovative, tailored tools, including the Integrated Rocket Sizing (INTROS) application, which is a launch vehicle design and sizing model that is used to assess advanced concepts. This tool has undergone almost a decade of development and is based on an architectural breakdown structure, with potential systems and subsystems from which to select. A database of mass estimating relationships is used to calculate the mass of conceptual architectures. INTROS accuracy is verified directly by modeling historical and existing launch vehicles.

The launch vehicle design developed in INTROS provides a basis for further analysis by the Launch Vehicles Analysis (LVA) program, which is a stand-alone application that provides extremely fast structural design and analysis. It does not use weight estimating or scaling routines but, rather, uses engineering methods based on material properties, load factors, aerodynamic loads, stress, elastic stability, and so forth. The LVA application has been in development for more than two decades and has been validated against the Atlas family of expendable launch vehicles. These and other tools provide confidence in the design proposed. 
As a final example, one of the most sophisticated tools is the modeling and simulation capability provided by the Virtual Integrated Performance Analysis (VIPA), which provides valuable data about machine/machine interface (Fig. 7) and human/machine interactions (Fig. 8) by allowing a subject to interact with a computer-aided design (CAD) animation. The VIPA capability projects a two-dimensional world into a virtual three-dimensional space, where the operator can interact with the design drawing. It allows design engineers to determine such things as whether clearances are adequate for potential onboard maintenance activities and where to route lines. It provides confidence that interfaces are in synch, and that mockup hardware generated as another design step will be of sufficient fidelity to appropriately inform manufacturing and operability decisions.

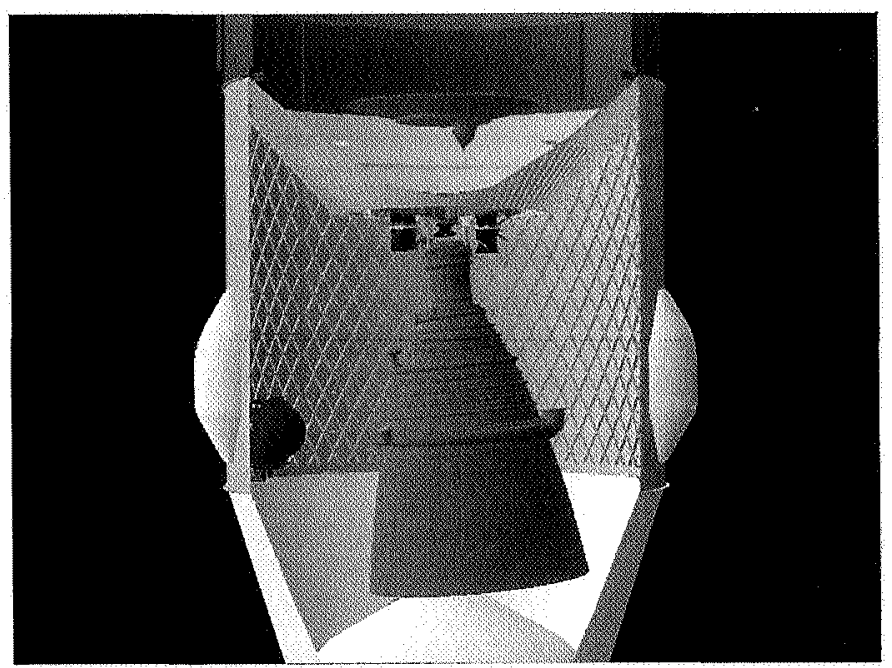

Fig. 7. Clearance check of J-2X engine bell within upper stage.

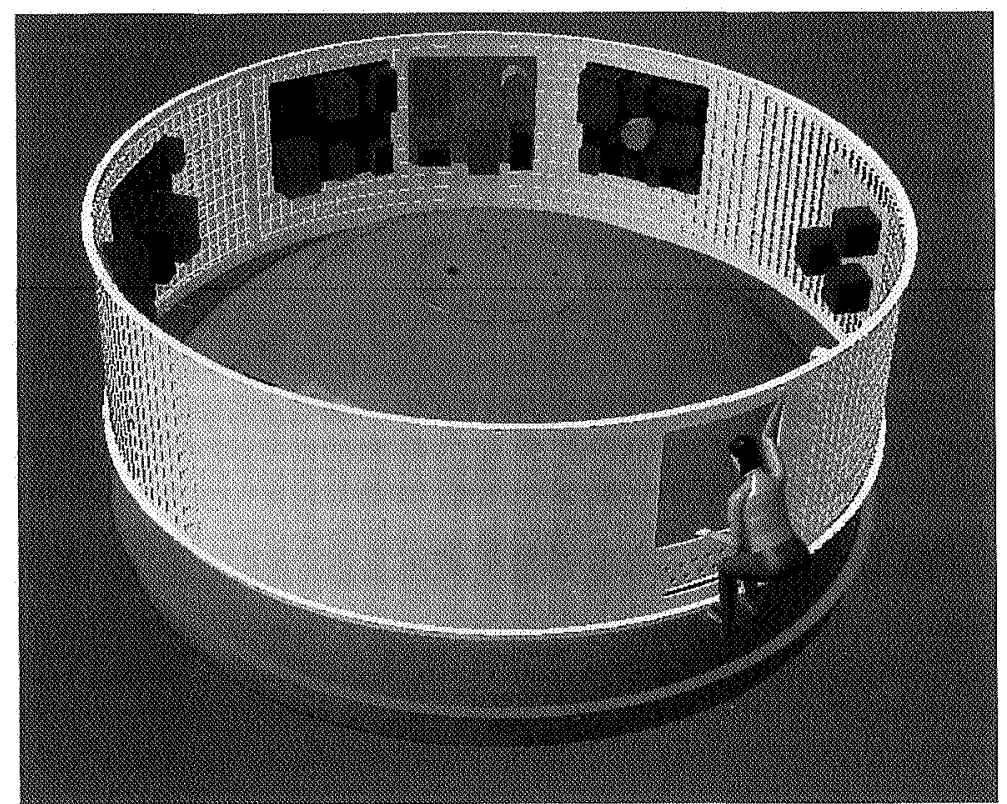

Fig. 8. Virtual ground operator entering interstage connection ring. 
As part of an integrated collaborative environment, the ability to fly the conceptual vehicle in cyberspace - combined with statistical studies of vehicle past performance, wind tunnel testing (see Fig. 9), and a series of ascent and orbital flight tests - is a powerful addition to the engineers' suite of design assets. While a sound methodology and cutting-edge tools are vitally important, there is no substitute for the primary engagement of real-world experience. NASA is marshalling its resources to help a new generation of spacecraft developers and operators get that hands-on experience and to deliver new capabilities, while planning carefully for how the transition from design to development to fielding will unfold.

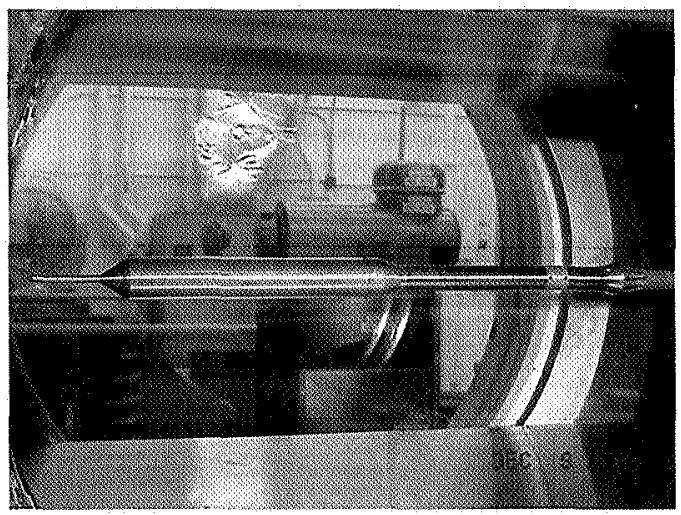

Fig. 9. Visualization studies a re conducted using scale models, such as this integrated stack.

\section{Transitioning Tradition}

Over the past decade, volumes of studies have been produced on potential systems to replace the Space Shuttle and to strike out on new missions. A number of advanced technologies have been pursued. As the Agency hones its plan, mindful of the "pay as you go" mandate, simpler solutions have come to light as promising paths to safe, reliable, and cost-effective space transportation systems. This bedrock foundation of decades of experience, combined with the best practices of systems engineering, position the Ares I for mission success.

Perhaps one of the strongest allies for the Ares I is the Space Shuttle Program, which works closely with the Constellation Program to ensure an efficient, effective transition of needed assets from a $20^{\text {th }}$ century system to a $21^{\text {st }}$ century fleet. Reflecting the importance of a smooth transition, the Exploration Launch Projects' First Stage Element Office is collocated with the Shuttle Reusable Solid Rocket Booster Propulsion Office. The Shuttle Program shares performance information gathered during ground testing (see Fig. 10) and actual flights. As another example, Exploration Launch Projects key personnel are involved in the Shuttle Flight Readiness Review (FRR) process to understand the goals and objectives, as well as to discover potential efficiencies for the Ares I operations phase. 


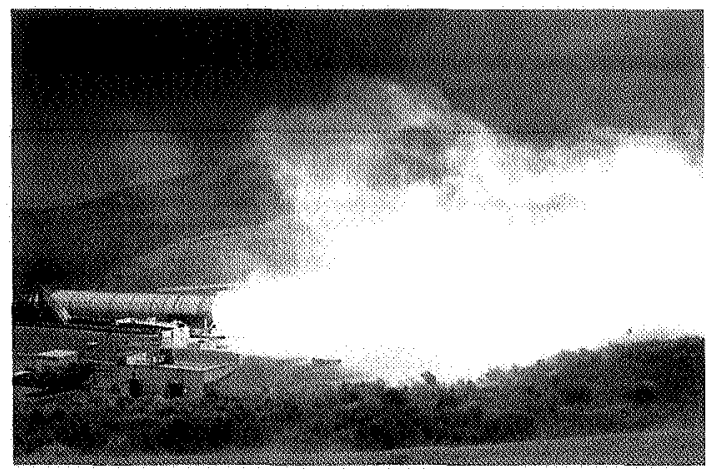

Fig. 10. Reusable Solid Rocket Booster static test firing, April 2006.

Processing the Space Shuttle for flight is a labor-intensive process. As is discussed above, the Ares I processing flow promises to be more streamlined and straightforward. NASA is actively determining the best way to make an orderly transition from one system to another over the next few years. ${ }^{12}$

Developing a learning culture that builds on its heritage while bringing innovation to life, demands that designers and operators integrate their efforts for maximum effect, in this case, reducing life-cycle costs so that the Ares I and its companion ship, the Ares V, are truly suitable for the long-term human exploration of space.

In these and a number of other ways, the Ares I effort leverages the best of the past as a prime riskreduction strategy. For example, NASA's one-of-a-kind manufacturing, testing, and launching facilities offer an infrastructure that can accommodate enormous tanks and structures (see Fig. 11), the most powerful U.S. rocket engines, and the integrated stack's ground and missions operations, along with the associated labor and logistics networks required for this specialized work. While this effort progresses, modifications to existing facilities will be made ready for the first test flight in 2009 , followed by a series of suborbital and orbital flights on the route to operating a new space transportation capability for the Nation's future missions.

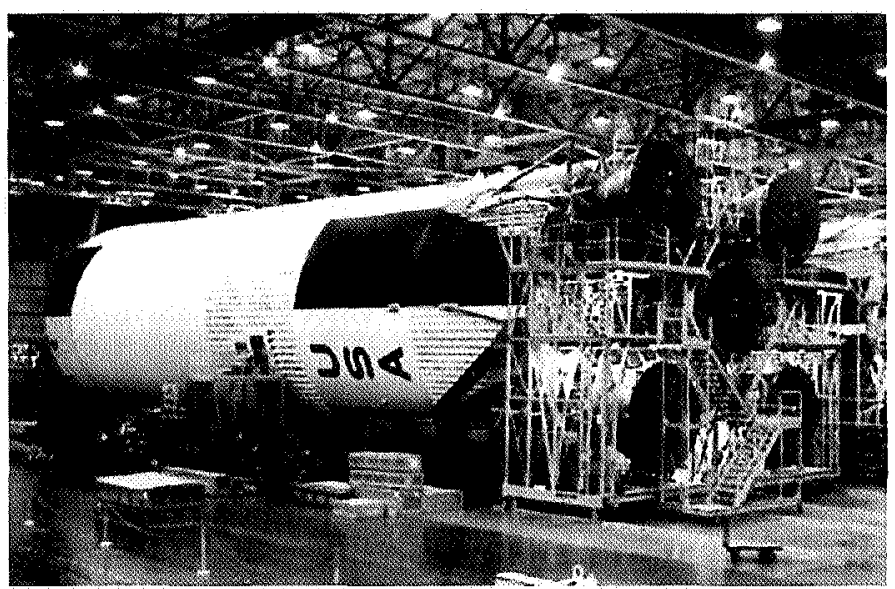

Fig. 11. NASA's Michoud Assembly Facility manufactured the Saturn V. 


\section{Conclusion}

NASA's budget comprises less than 1 percent of the Federal budget, yet its finite resources have a proven record of yielding discoveries with infinite possibilities. Lowering the life-cycle costs of transportation systems will help sustain the human exploration of space. Instituting rigorous systems engineering principles and practices, and nurturing a learning culture, exemplify the Agency's commitment to fiscal accountability, delivering the best value for the investment, and fulfilling the goals and objectives set forth in the U.S. Vision for Space Exploration.

Human space flight is recognized as a strategic capability with implications for National security and economic expansion. The majority of taxpayers polled support space exploration. ${ }^{13}$ The steps NASA is taking today are designed to maximize the unique infrastructure and talent residing in the current workforce, while stimulating commercial service providers to proffer fresh solutions. The Nation's commitment to the long-term exploration of space is embodied in the conceptual designs that will deliver explorers to orbit for trips that will open new routes to unimaginable discoveries.

\section{References}

1. "NASA Selects Crew and Cargo Transportation to Orbit Partners," August 18, 2006, NASA News, www.nasa.gov

2. United States Vision for Space Exploration, January 2004, www.nasa.gov.

3. Exploration Systems Architecture Study, Final Report, Technical Manual 2005-214062, November 2005, www.sti.nasa.gov.

4. "NASA Awards Contracts for Constellation Program Study," July 26, 2006, NASA News, Www.nasa.gov.

5. NPR 7120, NASA Program and Project Management, 2005.

6. CxP 72015, NASA Exploration Launch Projects Configuration Management Plan, 2006.

7. NPR 7123, NASA Systems Engineering Processes and Requirements, 2006.

8. NASA/TP-2001-2100992, Launch Vehicle Design Process: Characterization, Technical Integration, and Lessons Learned, J.C. Blair, et al, p. 150.

9. CxP 00001, NASA Constellation Architecture Requirements Document, 2005.

10. CxP 72032, Crew Launch Vehicle Operational Concepts Document, 2006.

11. NASA Exploration Launch Projects Systems Engineering Management Plan, 2006.

12. "Exploration Bridge," Aviation Week and Space Technology, July 24, 2006, p. 17.

13. "Public Divided Over Money Spent on Space Shuttle Program: American's Continue to Rate NASA Positively," June 30, 2006, Gallup News Service, http://poll.gallup.com. 


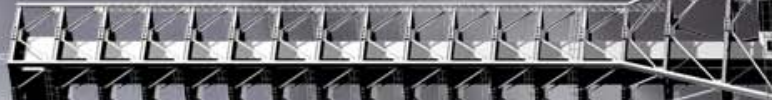

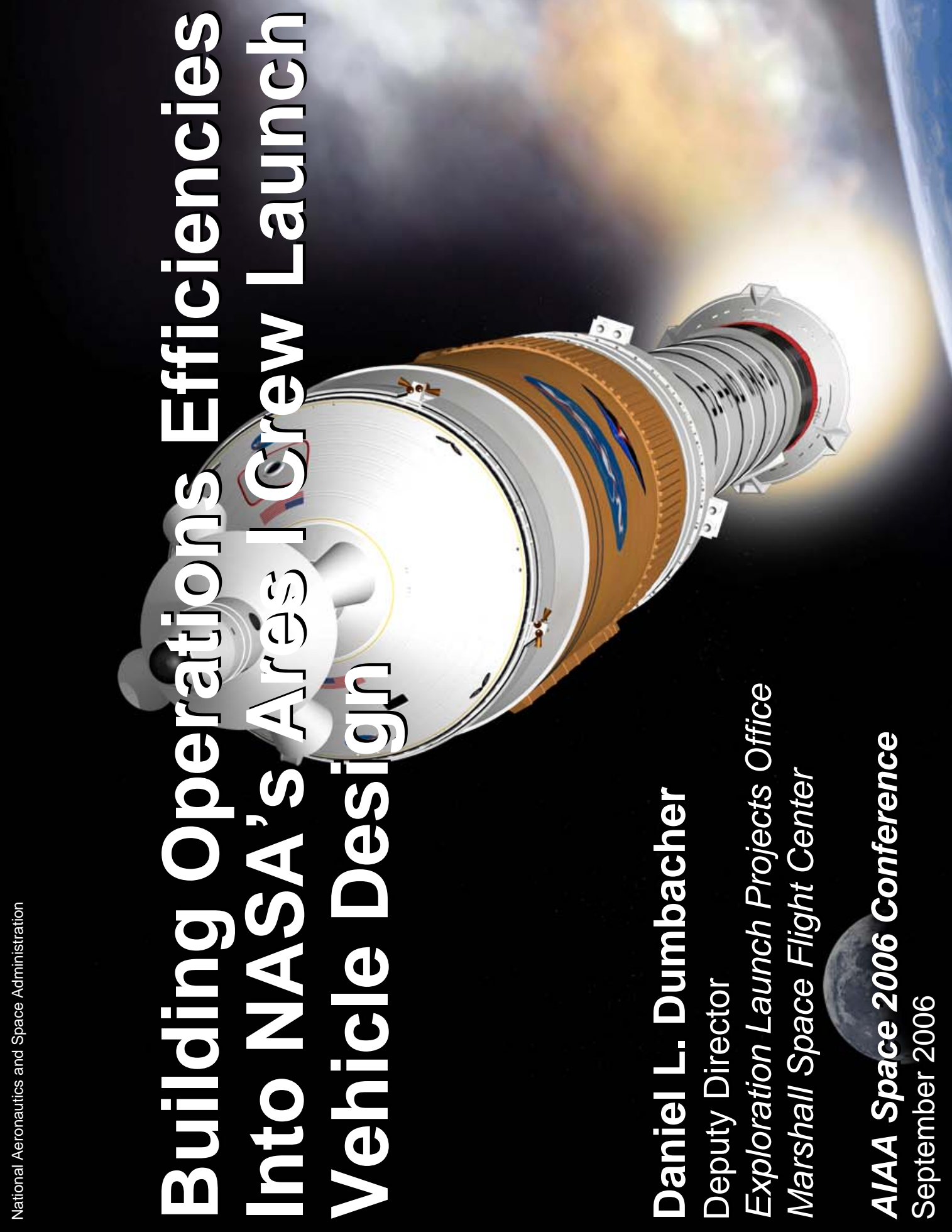




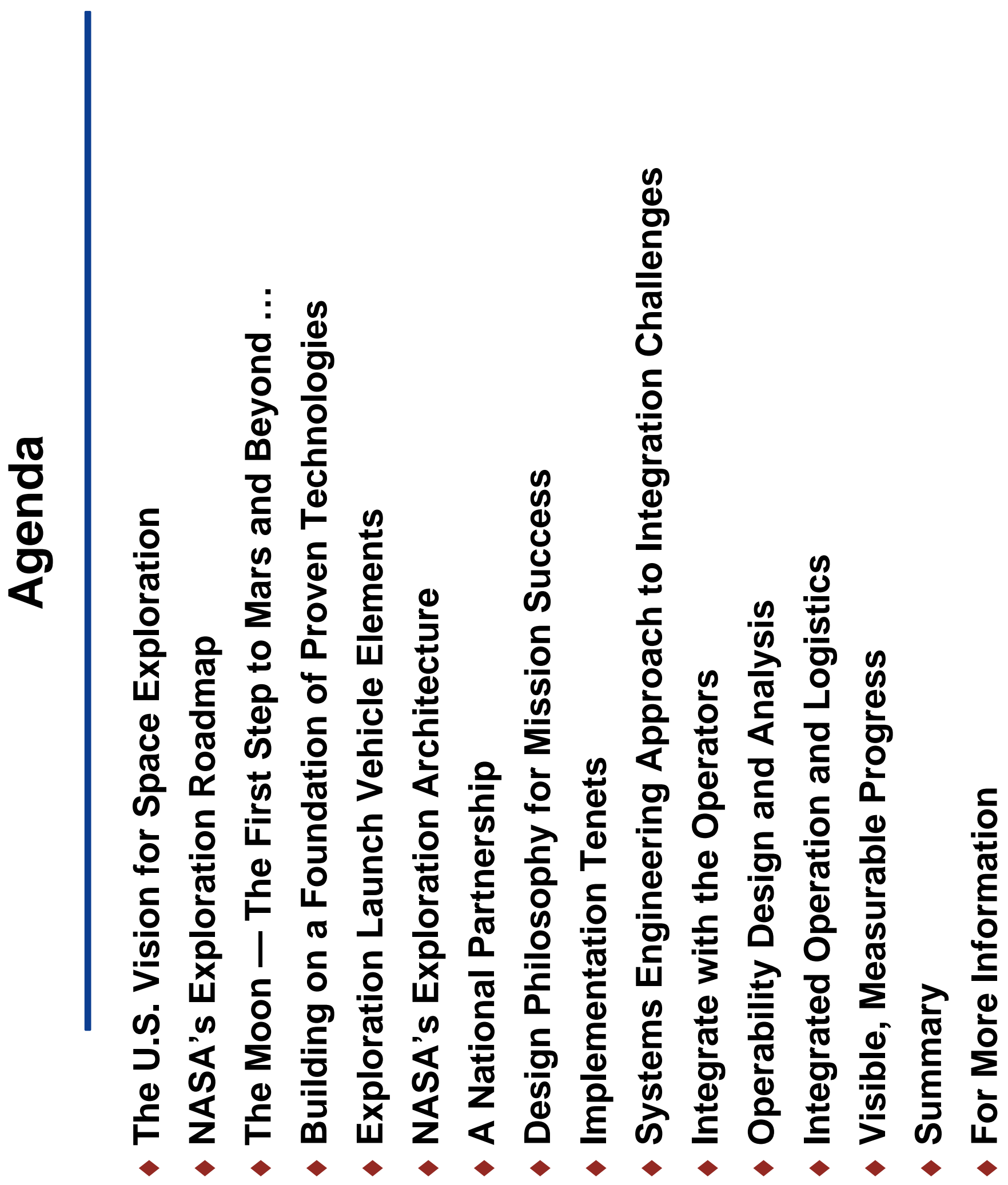




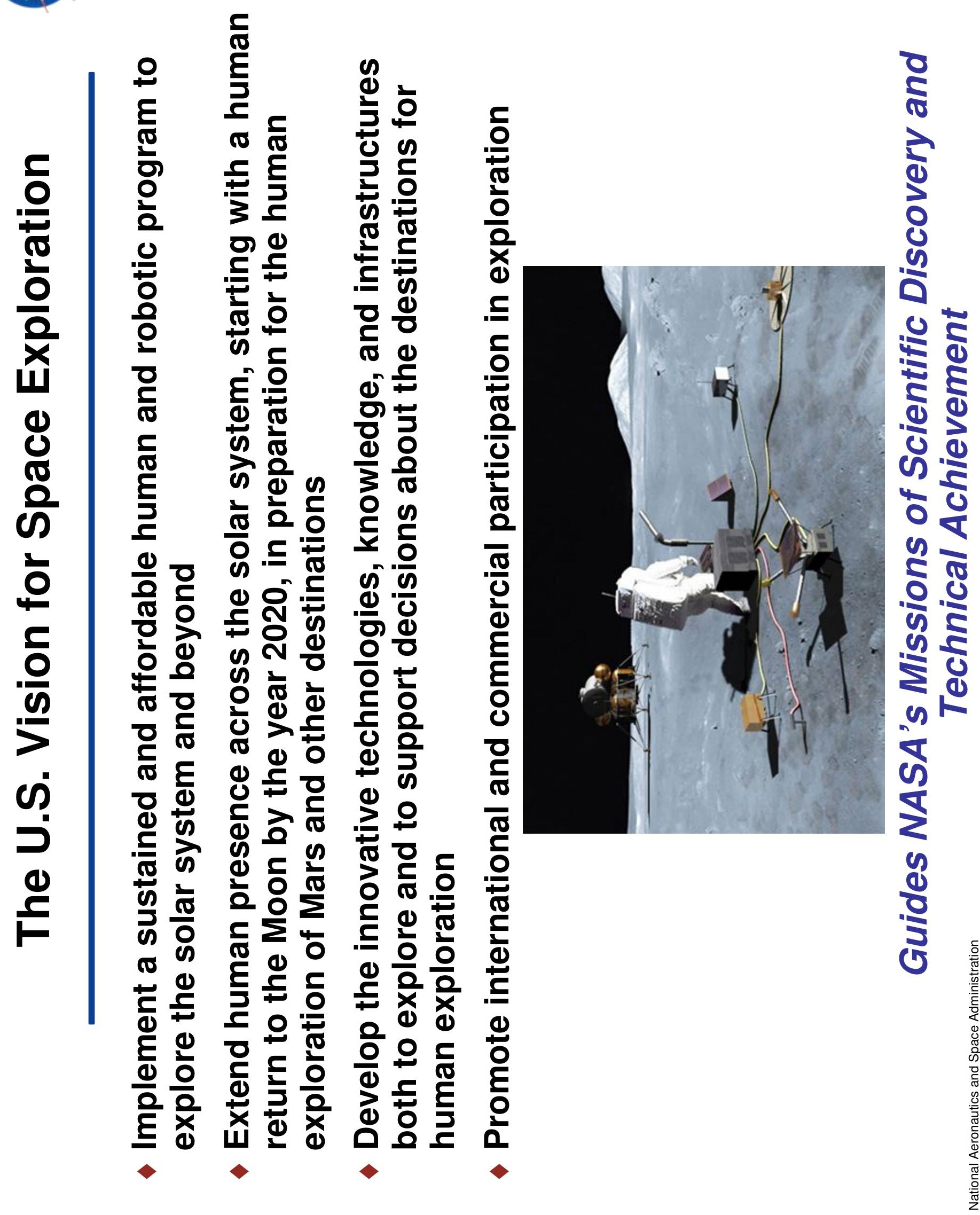




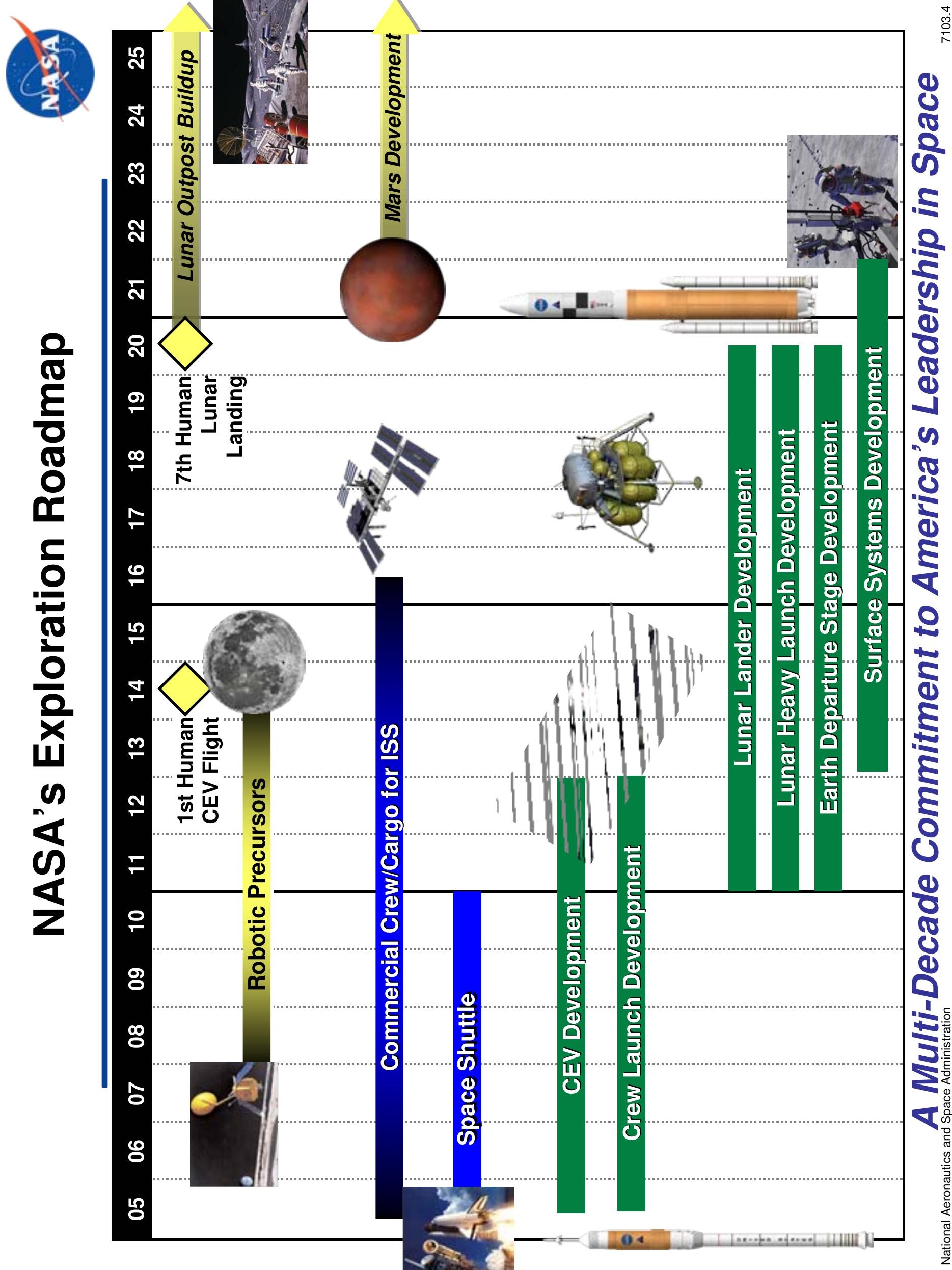




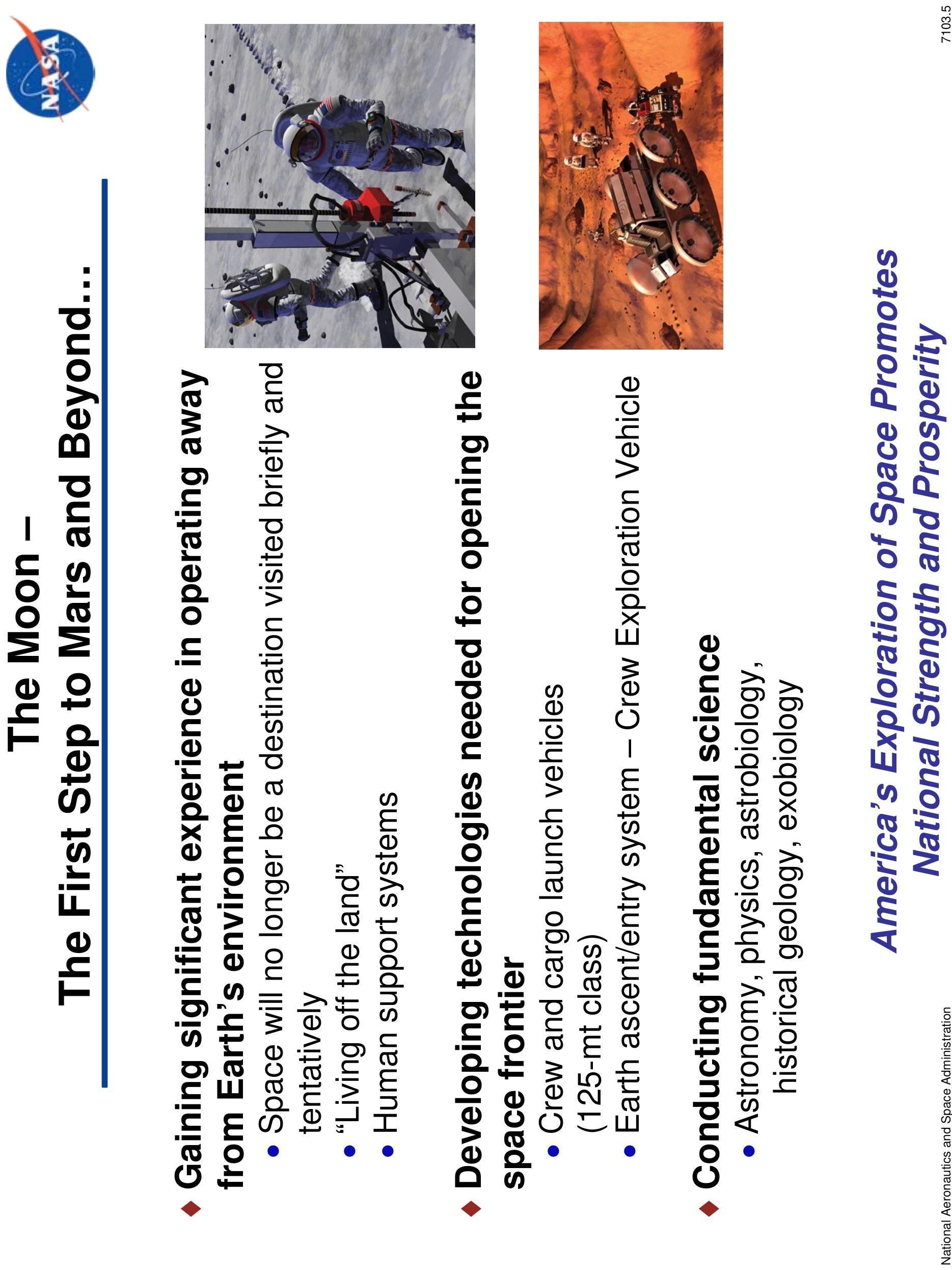




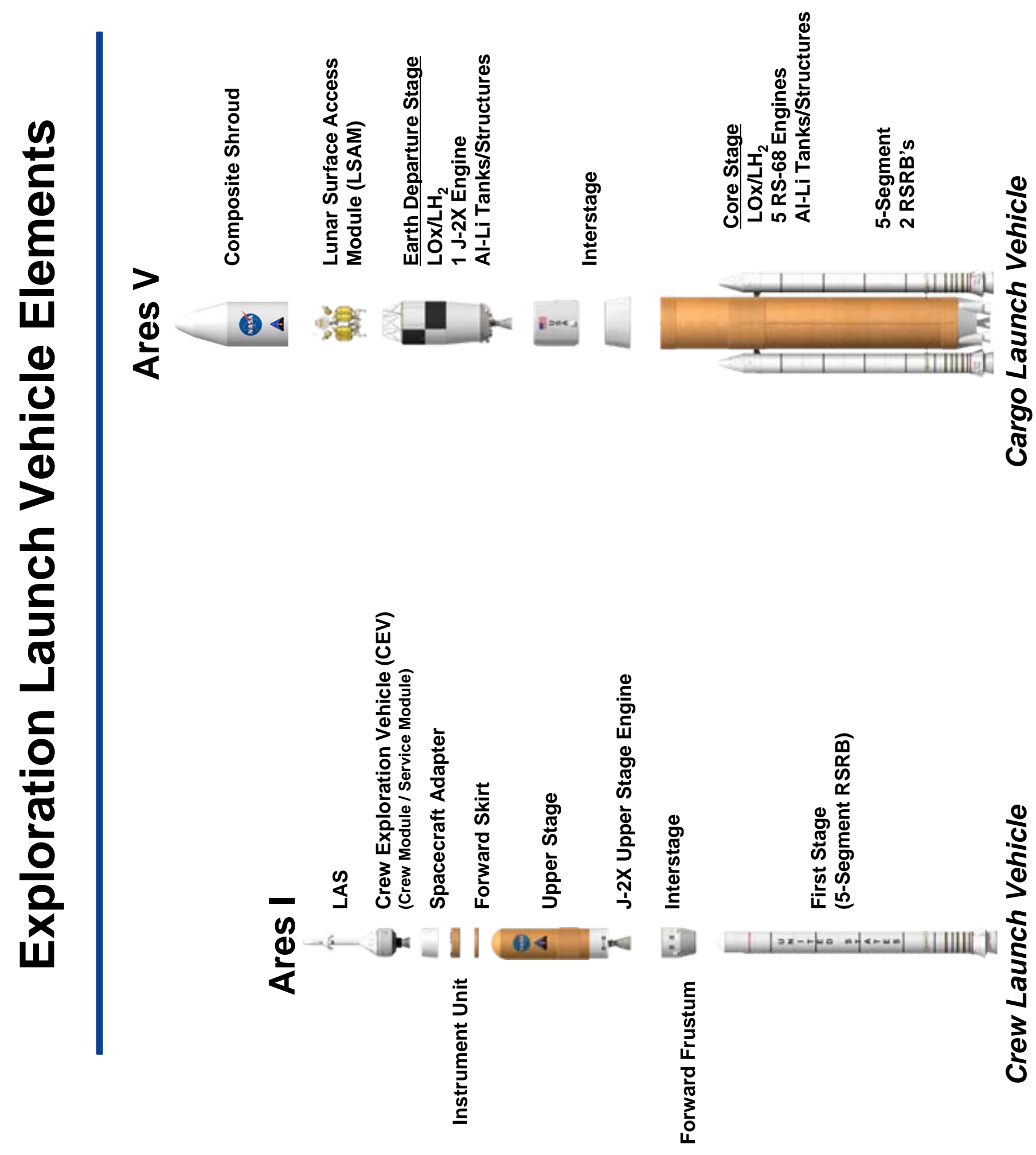


1

3

(d)

$\pm$

$\frac{2}{2}$

0

4

동

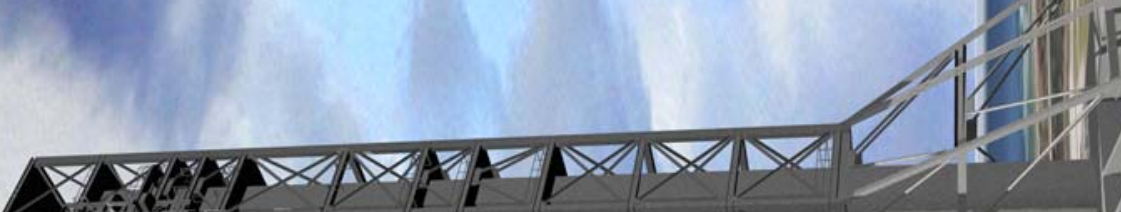

$\pi$

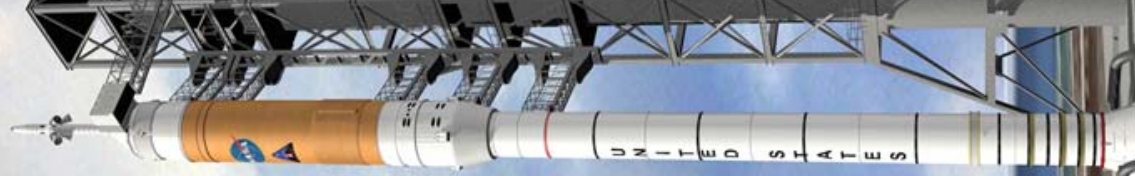



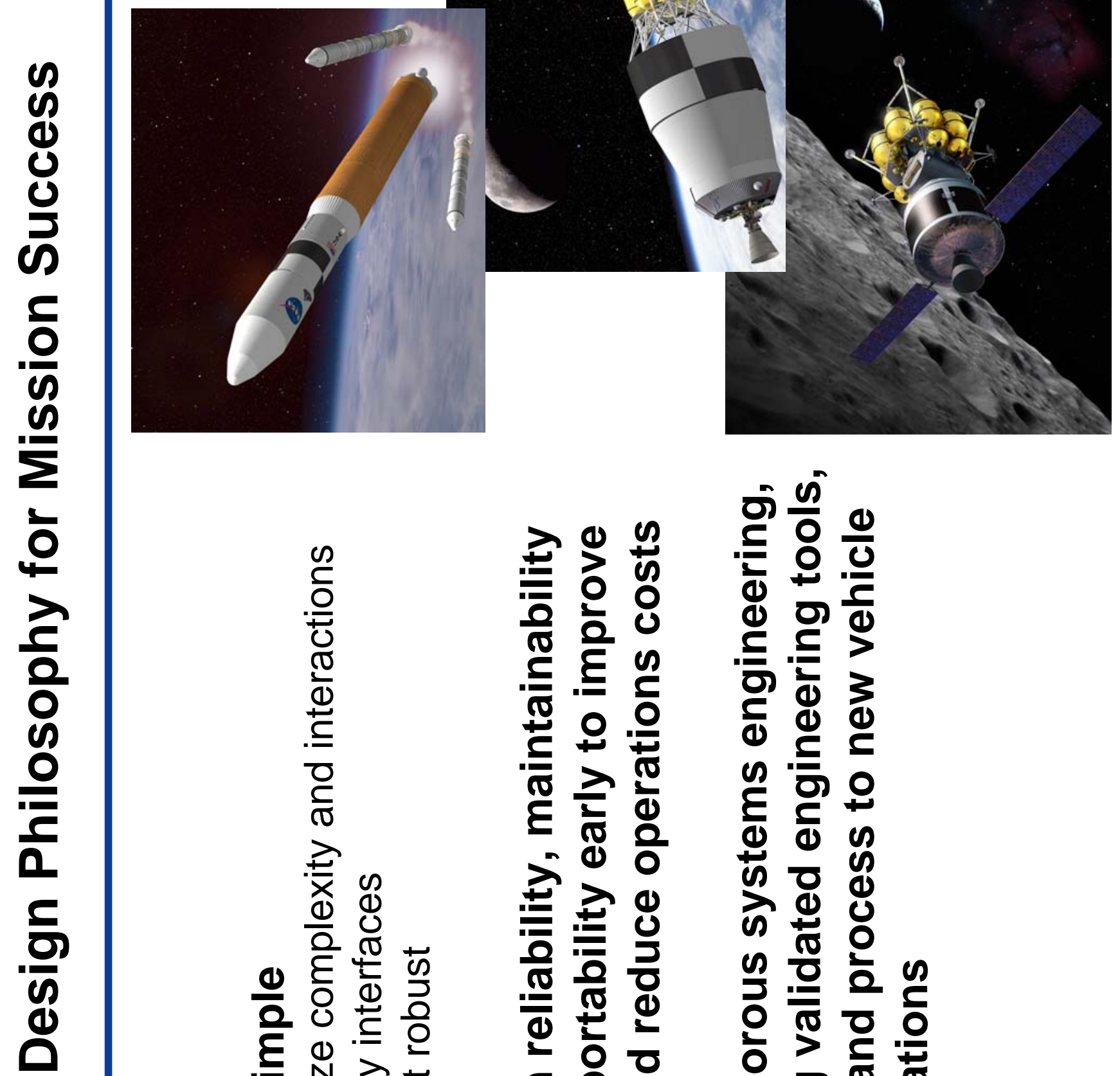

0
0
5
0
0
1
0
0
0
0
0
0
0
0
0
0
0
0
0
0
0
0
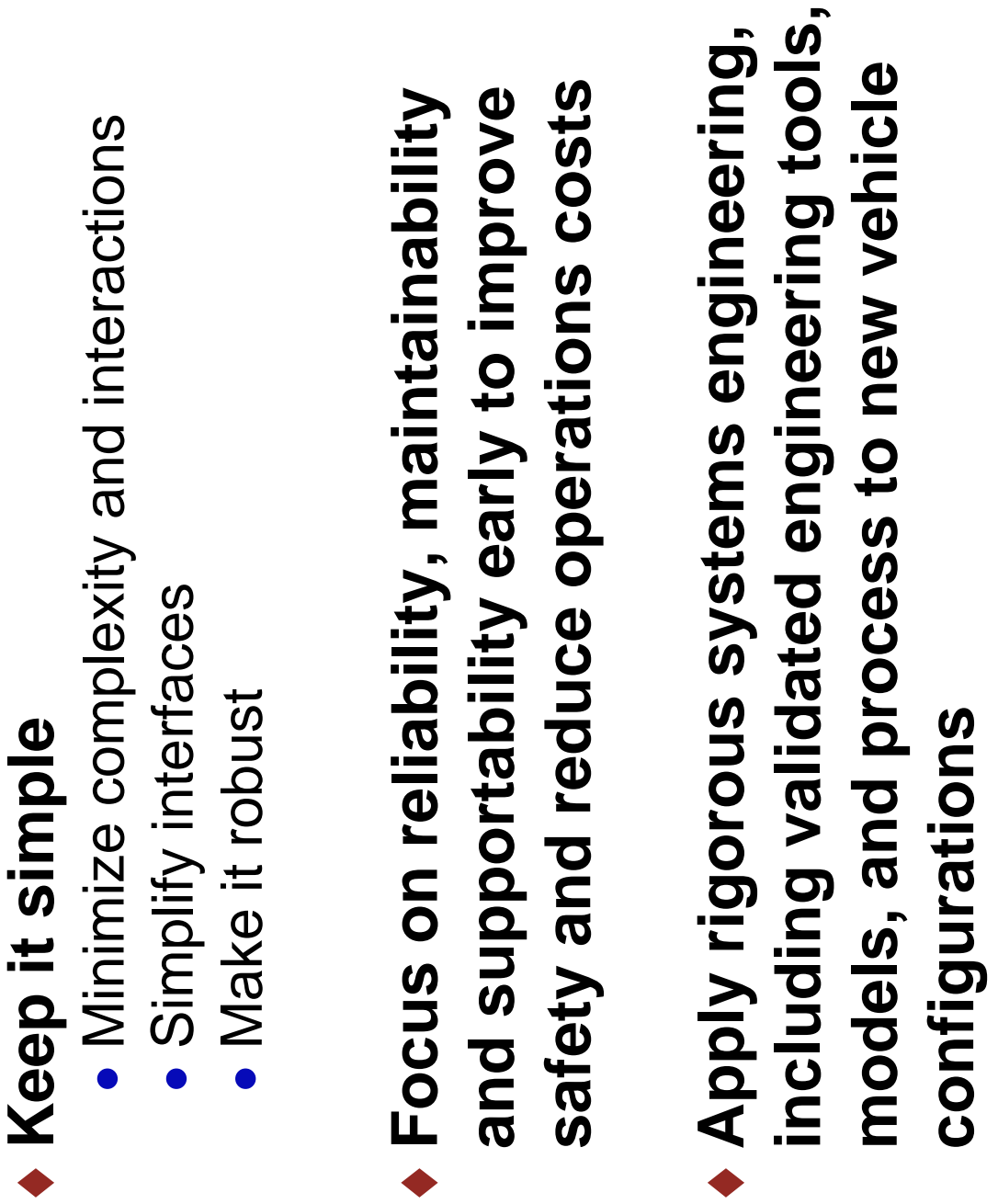


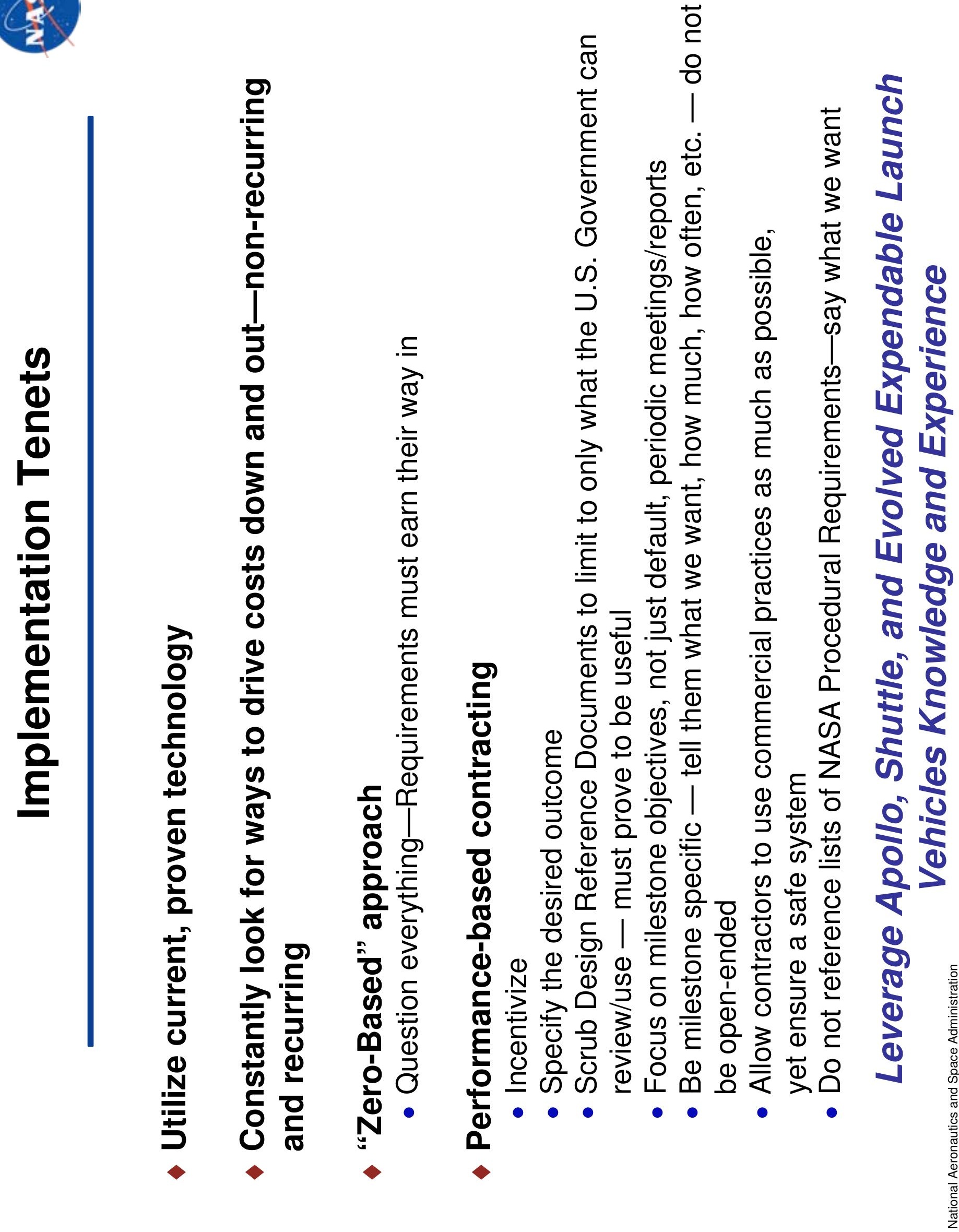




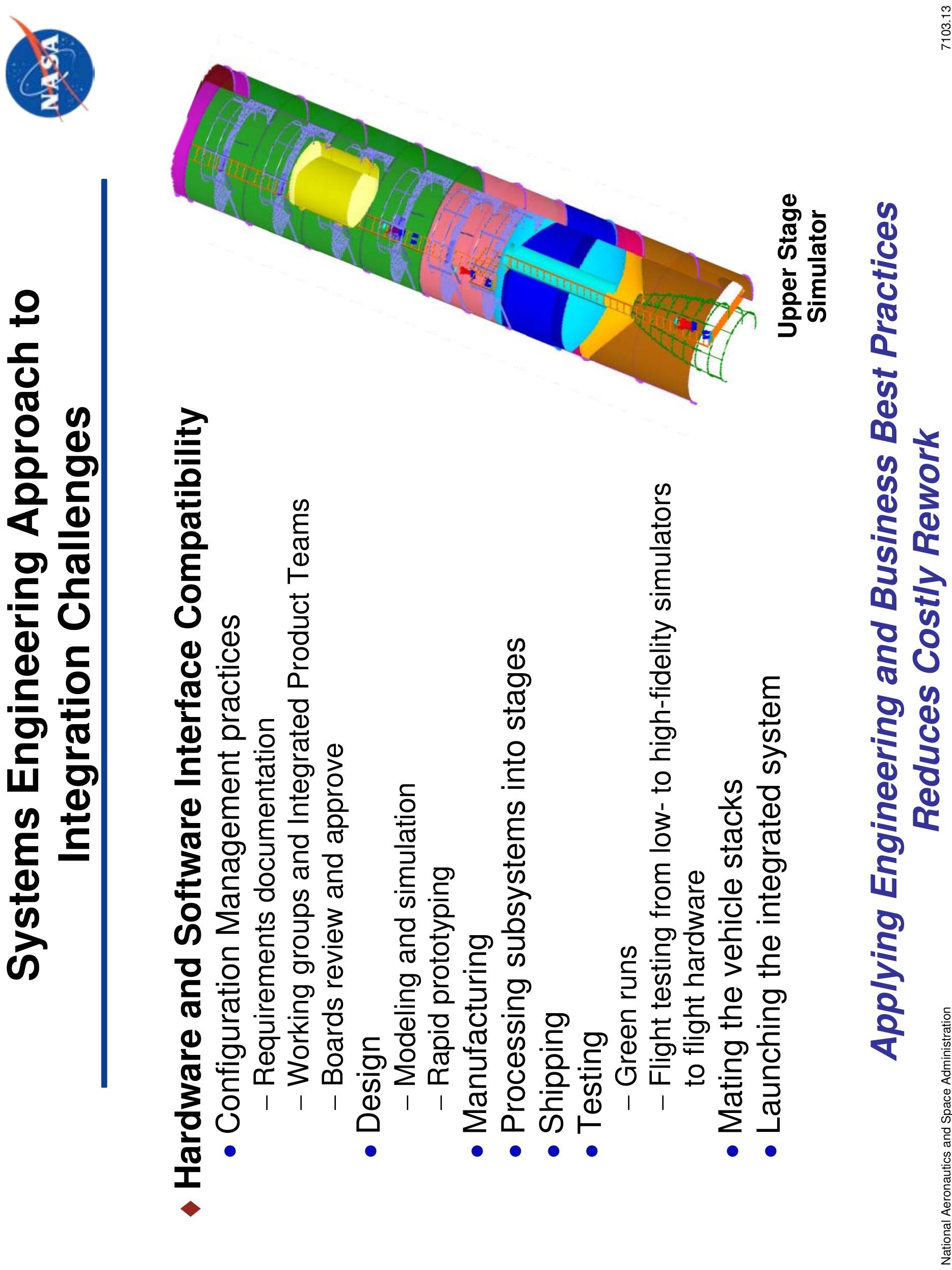



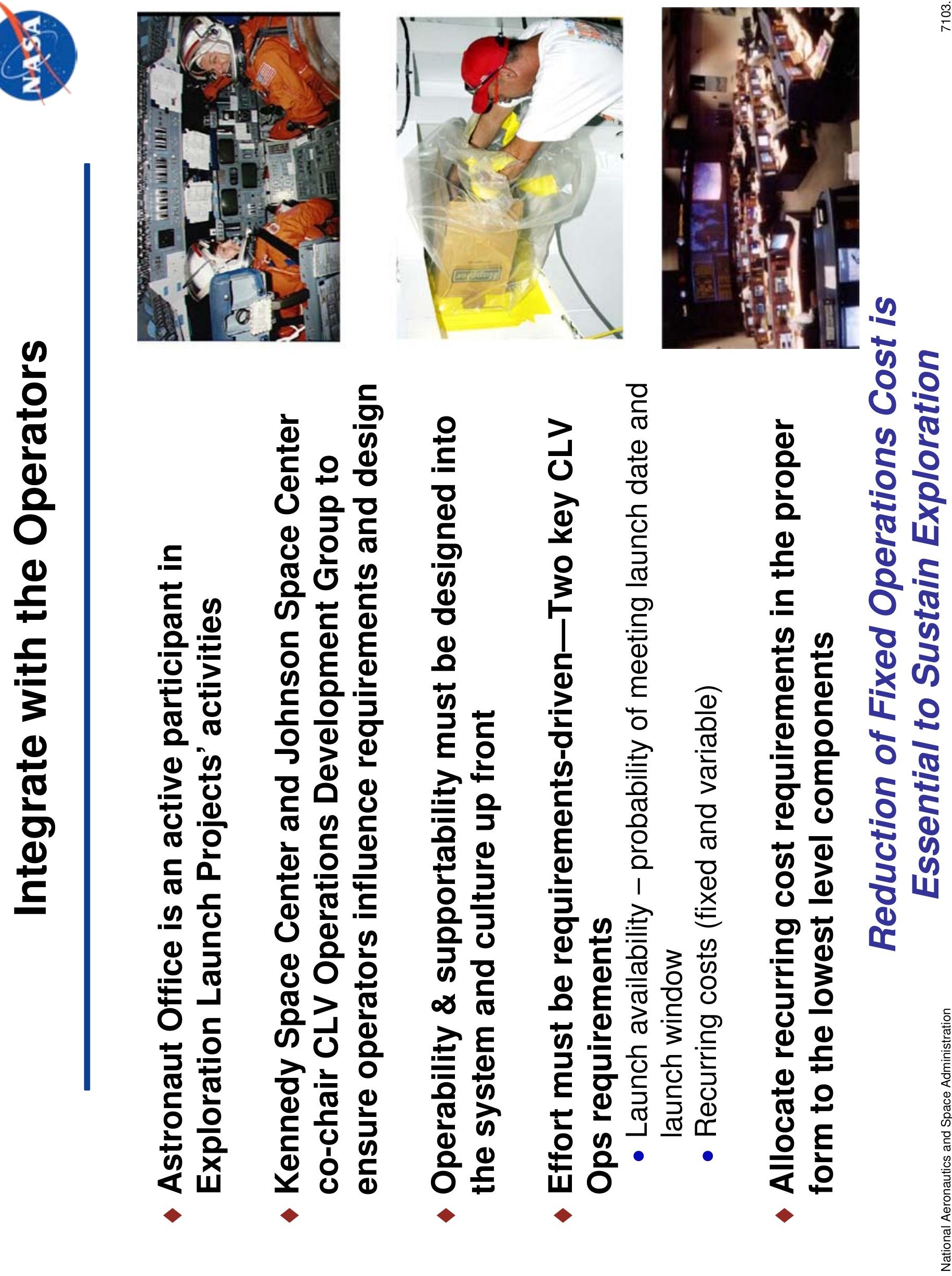


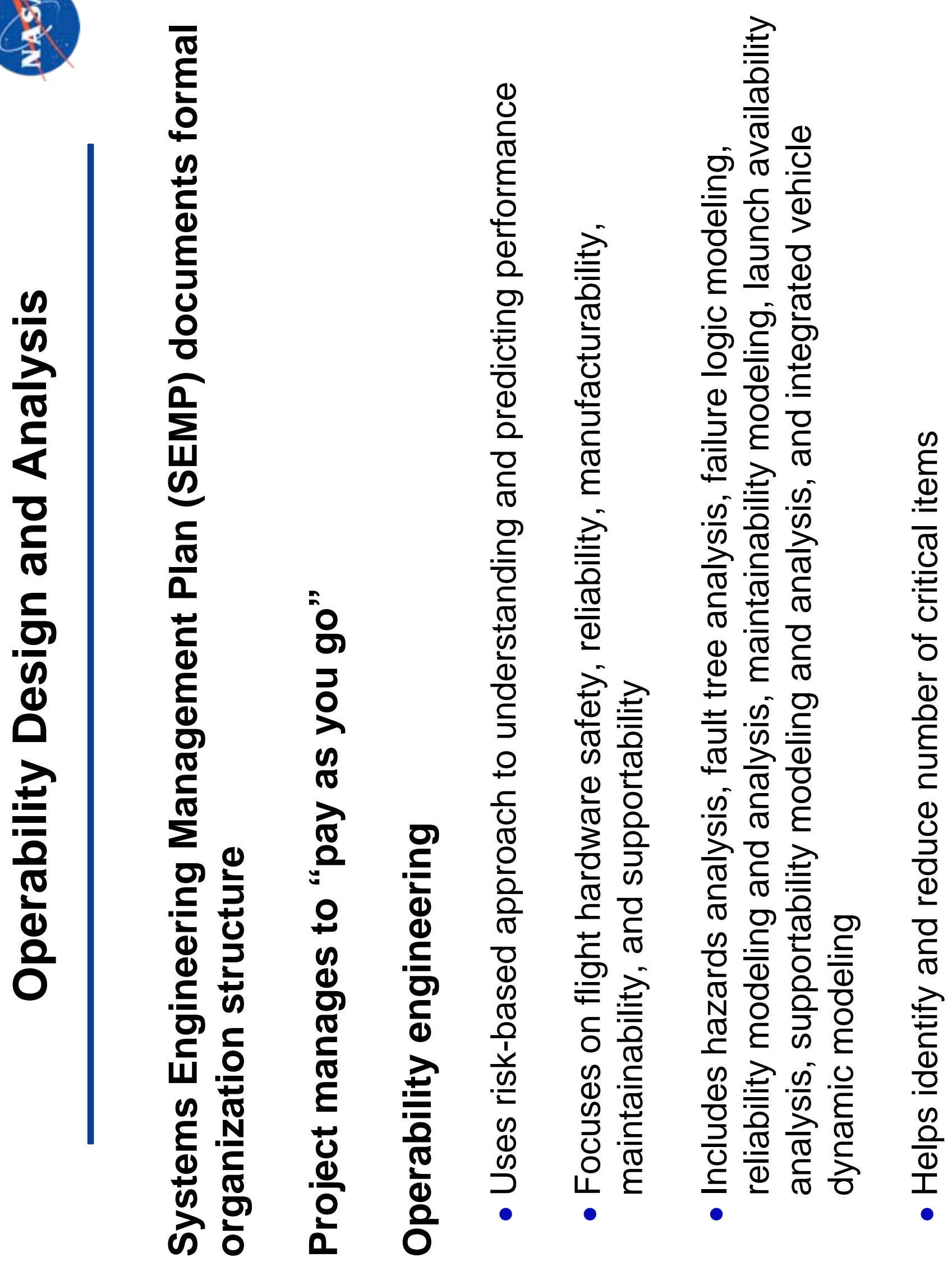




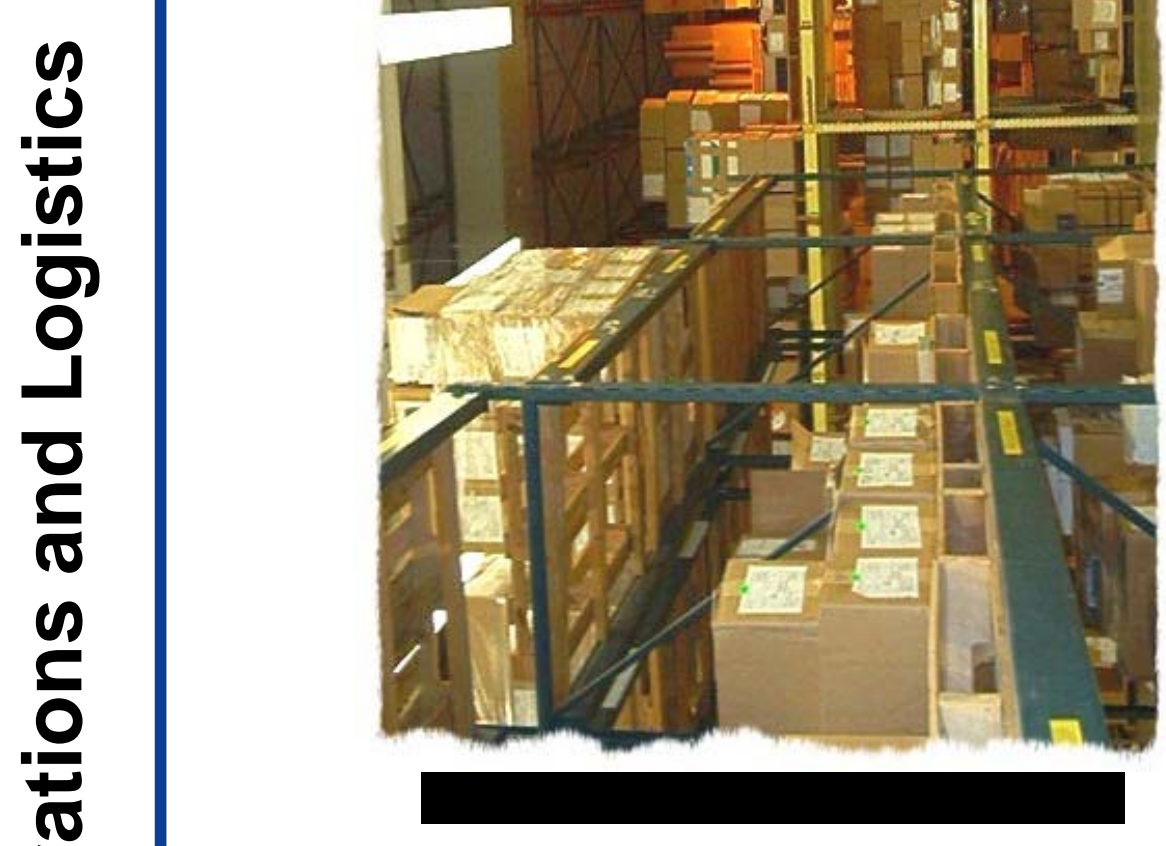



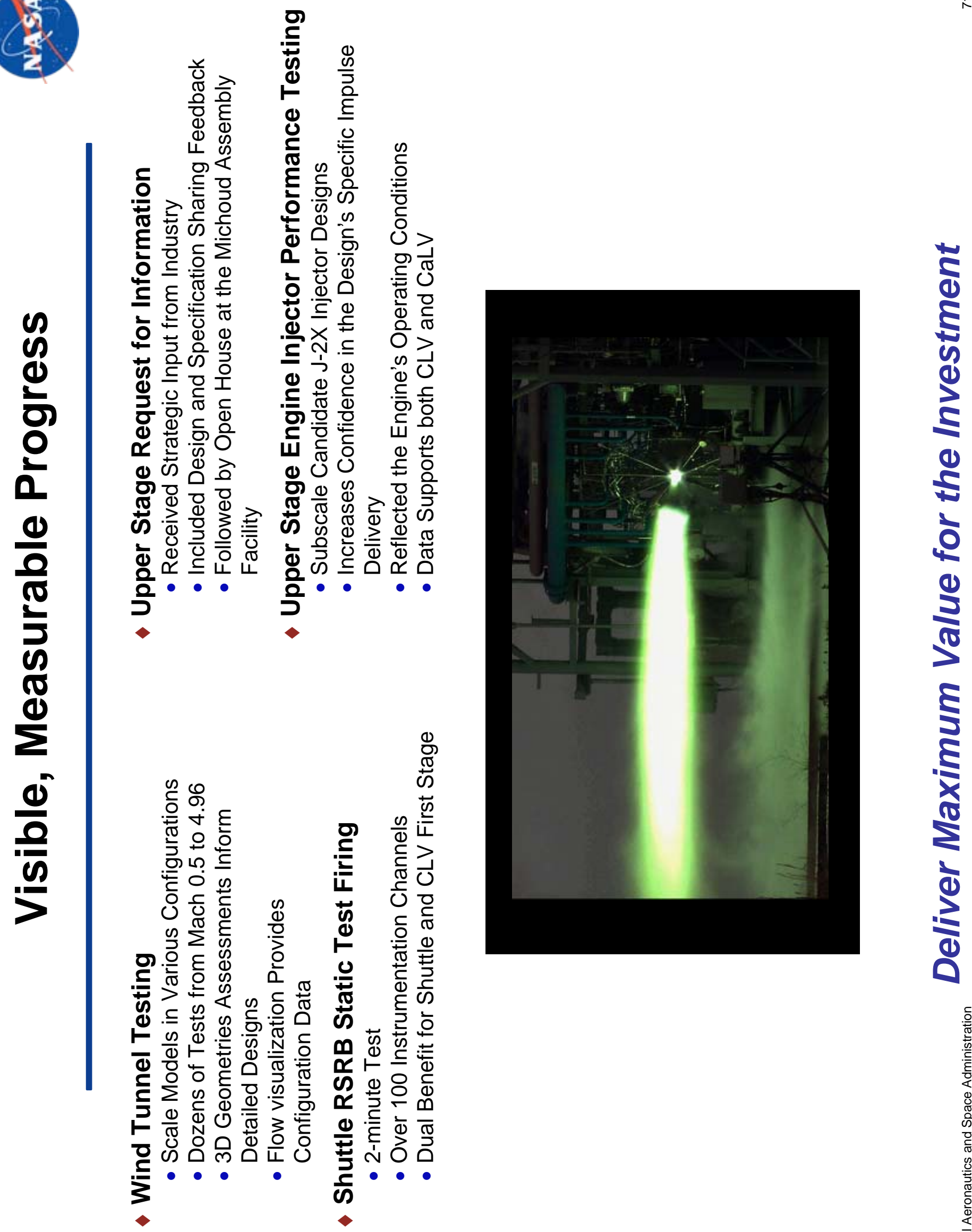


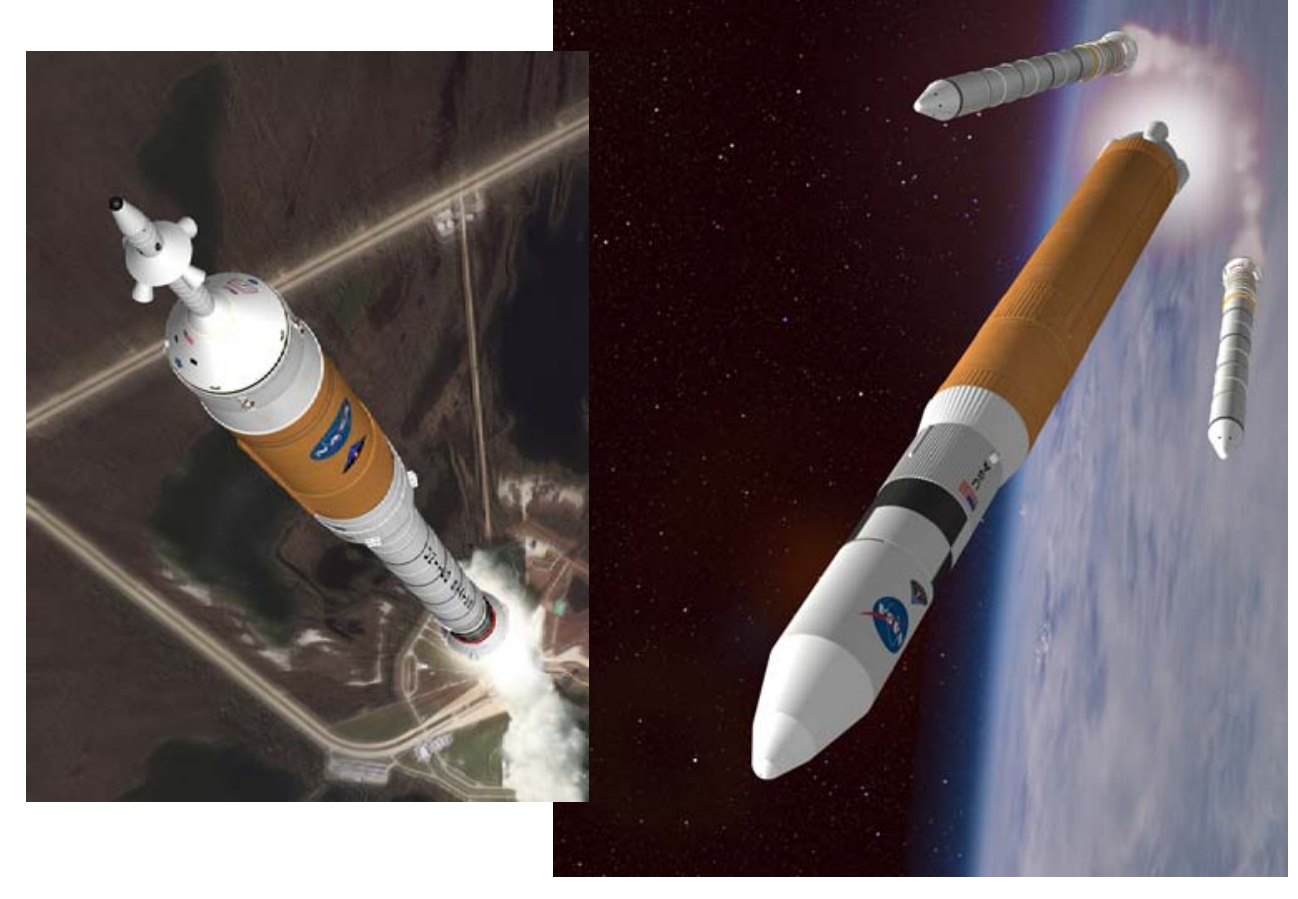

$\stackrel{\infty}{+\infty}$

E

늠

$\frac{2}{2}$

은 음

둥

ช

क

రิ๊

오응 으

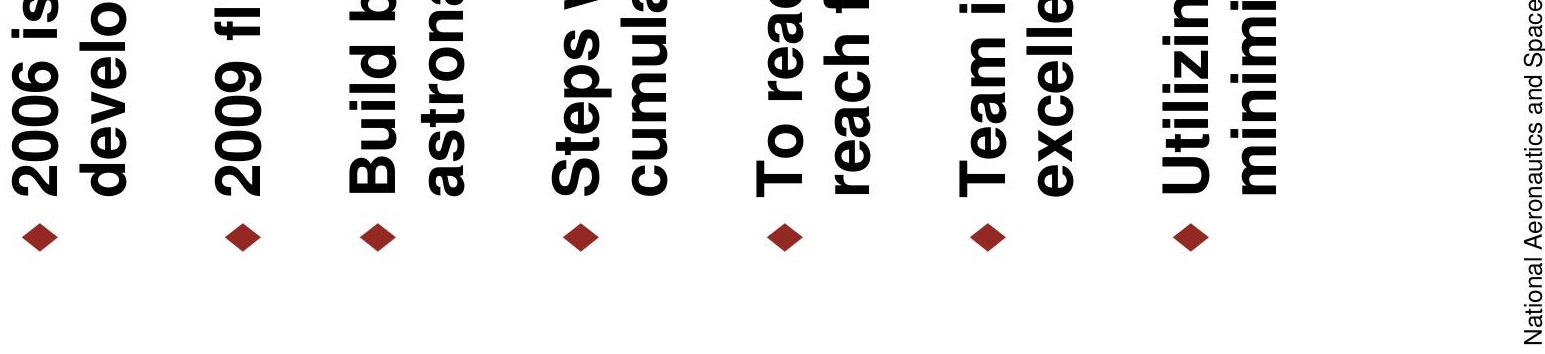


()

()

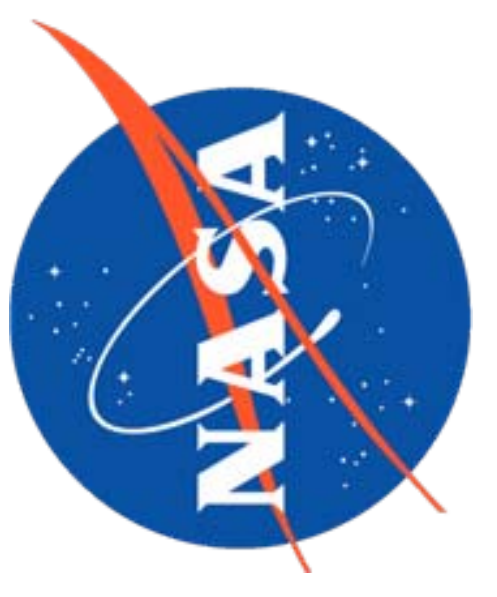

3 